\title{
Research Paper \\ The efficacy of emotional regulation training in comparison with mindfulness training on cognitive flexibility and parent-child interaction in mothers of children with mild mental retardation
}

\begin{abstract}
Citation: Jafarpour H, Akbari B, Shakerinia I, Asadimajreh S. The efficacy of emotional regulation training in comparison with mindfulness training on cognitive flexibility and parent-child interaction in mothers of children with mild mental retardation. $\mathbf{J}$ of Psychological Science. 2022; 20(107): 2125-2143.
\end{abstract}

Hassan Jafarpour ${ }^{1}$, Bahman Akbari ${ }^{2}$, Iraj Shakerinia ${ }^{3}$, Samereh Asadimajreh ${ }^{4}$

1.Ph.D Student in Psychology, Department of Psychology, Rasht Branch, Islamic Azad University, Rasht, Iran.

2. Associate Professor, Department of Psychology, Rasht Branch, Islamic Azad University, Rasht, Iran.

3. Invited Associate Professor, Department of Psychology, Rasht Branch, Islamic Azad University, Rasht, Iran and Associate

Professor, Department of Psychology, University of Guilan, Rasht, Iran.

4. Assistant Professor, Department of Psychology, Rasht Branch, Islamic Azad University, Rasht, Iran.
URL: https://psychologicalscience.ir/article-1-1203-fa.html
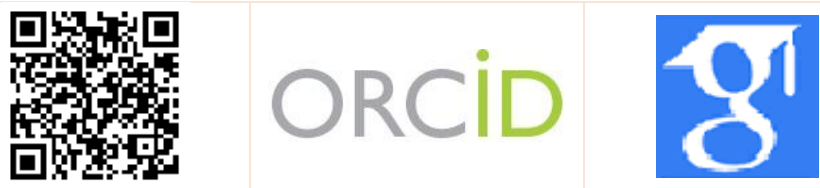

$\underline{10.52547 / J P S .20 .107 .2125}$

\section{A R T I C L E I N F O A B S T R A C T}

Keywords:

Cognitive flexibility,

Parent-child interaction,

Emotional regulation,

Mindfulnes,

Mental retardation

Received: 03 Apr 2021

Accepted: 06 Jun 2021

Available: 21 Jan 2022
Background: Background studies show that emotional regulation and mindfulness training have each led to improved cognitive flexibility and parent-child interaction; But it is not yet clear which of these interventions can be most effective over time.

Aims: The aim of this study was to compare the effectiveness of emotional regulation and mindfulness training on cognitive flexibility and parent-child interaction of mothers with children with mild mental retardation.

Methods: The research was quasi-experimental with pre-test, post-test design and follow-up with a control group. The statistical population of the study included all mothers with children with mild mental disabilities who referred to exceptional schools in Rasht in the academic year of 2019-2020. 36 people were selected by convenience sampling method and randomly divided into three groups of 12 people. The experimental groups were trained in emotional regulation ( 8 sessions of 90 minutes) and mindfulness (8 sessions of 90 minutes). Research instruments included the Cognitive Flexibility Questionnaire (Dennis and Vanderwall, 2010) and the Parent-Child Relationship Scale (Pianta, 1994). Data analysis was performed using repeated measures ANOVA.

Results: Emotional regulation and mindfulness training were effective in improving cognitive flexibility and parent-child interaction and their components in the post-test and follow-up stages; Also, in the follow-up stage, no significant difference was observed between the two interventions in these variables $(\mathrm{P}<0.01)$.

Conclusion: According to the results, it can be said that training in emotional regulation and mindfulness by promoting emotional reconstruction, reducing negative self-referential processing and increasing the ability to perform purposeful behaviors, awareness of current experiences and returning attention to cognitive system and more efficient information processing, finally, improved cognitive flexibility and parent-child interaction of mothers with children with mild mental retardation.

* Corresponding Author: Bahman Akbari, Associate Professor, Department of Psychology, Rasht Branch, Islamic Azad University, Rasht, Iran.

E-mail: bakbari44@yahoo.com

Tel: (+98) 9111361102

2476-5740/ () 2021 The Authors. This is an open access article under the CC BY-NC-ND license

(https://creativecommons.org/licenses/by-nc/4.0/). 


\section{Extended Abstract}

\section{Introduction}

Having a child with an intellectual disability causes a lot of stress on family members, especially on the mother (Moradikia et al., 2017). Parents of these children report more stress and depression that leads to a vicious cycle of negative consequences for these children and the well-being of their family (Lo et al., 2017). Cognitive flexibility is one of the skills that can protect parents of children with special needs to some extent from parental stress (Curran et al., 2019). The results suggest that mothers with children with special needs have poor cognitive flexibility (Shalani et al., 2019). The interaction between parents and children is an important and vital relationship to generate security and love, which is a combination of behaviors, feelings and expectations that are unique to the parent and a particular child. This interaction is the child's first portrait of the world of communication and the feeling of love, security and intimacy is directly rooted in these relationships (Bireda \& Pillay, 2018).

Studies have suggested various solutions to improve cognitive, behavioral, and psychological problems in mothers of children with special needs, including training in area of emotional regulation (Matin et al., 2018; Javadian et al., 2018; Kamali et al., 2016) and mindfulness. (Safikhani et al., 2020; Ahmadi et al., 2019). Mothers of children with intellectual disabilities face many stresses and concerns; As a result, they have unfortunate consequences for their mental health and interaction with their child (Lo et al., 2017). Therefore, the provision of appropriate educational and therapeutic interventions is of great importance and necessity for them. Based on previous research, two approaches to teaching emotional regulation and mindfulness can improve quality of life, cognitive flexibility, and stress in these mothers. However, no studies were found in the background study that performed these two interventions in the field of mothers of children with intellectual disabilities. On the other hand, it is not clear which of these two educational programs is more effective in these mothers to improve cognitive flexibility and parent-child interaction, so that therapists can use it as initial treatment for these mothers. Therefore, the present study attempts to answer this question: which of the two educational programs for emotional regulation and mindfulness is more effective on cognitive flexibility and parent-child interaction of mothers with children with intellectual disabilities?

\section{Method}

The research method was quasi-experimental with a pretest-posttest design with a control group and a follow-up of five groups of three months. The statistical population of the study consisted of all mothers with children with mild intellectual disabilities who had been referred to special schools in Rasht in the academic year 2019-2020, of which 36 people were selected according to the available methods and randomly divided into three groups (two experimental group and a control group). In order to data collection: 1- Cognitive flexibility questionnaire and 2- Parent-child relationship scale were used, which have acceptable reliability and validity.

To conduct the investigation, upon receiving a letter of recommendation from the Vice Chancellor for Research, we referred to the Rasht Exceptional Education Department and obtained the necessary permits to conduct the investigation. Then, four exceptional schools in Rasht were referred and the mothers of the students who had a record there were selected and given a clear diagnosis of mild IQ based on the inclusion criteria. The enjoyment of mental health by mothers based on a clinical interview, a definitive diagnosis of mild intellectual disability (IQ between 50-55 and 70-75) based on a Wechsler IQ test in the student's record and the Informed consent to participate in the study as an inclusion criterion into account. The absence of more than two sessions in the total training courses and the non-completion of the questionnaires were also assessed as exclusion criteria.

After providing preliminary explanations with the purpose of investigating and obtaining the participation of the subjects and ensuring the confidentiality of the information and obtaining their informed consent; The subjects were randomly divided into two experimental groups and a control group. The three groups personally answered the questionnaires in the pretest phase and then the 


\section{Monthly Journal of Psychological Science}

Vol. 20, No. 107, Winter(February) 2022 experimental groups were trained in emotional regulation ( 8 sessions of 90 minutes each) and mindfulness ( 8 sessions of 90 minutes each), but the control group was in waiting list for intervention. At the end of the intervention, the three groups personally filled in the questionnaires again as posttest and, after a five-month post-test, the follow-up test was performed in the experimental and control group; At the end of the follow-up, an emotional regulation intervention with the aforementioned quality was performed for the control group. Finally, after data collection, the analysis was performed using a mixed analysis of variance with SPSS-22 software.

\section{Results}

In this study, 36 people participated in two intervention groups and a control group (12 people in each group). The results showed that the $\mathrm{F}$ amount of interaction effect (time * group) for the variables of total score of cognitive flexibility (66.635), perception of various options (15.063), perception of controllability (64.575), perception of justification behavior (14.184), closeness (59.883), dependence (36.756), conflict (25.428), positive relationship between parents and children (39.973) are significant $(p<0.01)$. This finding shows that the experimental and control groups differ significantly with respect to the research variables in the three stages of pre-test, post-test, and follow-up. Furthermore, their square for all the variables is more than 0.10 , which shows that the difference between the groups in society is large and significant.

Table 1. Results of the comparison of the mean values of the experimental groups in three stages of pretest, posttest and follow-up on cognitive flexibility of mothers with children with mild intellectual disability

\begin{tabular}{ccccc}
\hline Variable & Measurement step & Mean difference with control group & Standard error (SE) & P-Value \\
\hline \multirow{3}{*}{ Cognitive flexibility total } & Pre-test & -1.333 & 1.064 & 0.686 \\
& Post-test & -5 & 2.316 & 0.094 \\
& Follow up & -1.667 & 2.329 & 0.756 \\
Perception of different & Pre-test & 0.417 & 1.266 & 0.942 \\
options & Post-test & -2.083 & 1.953 & 0.541 \\
& Follow up & -0.583 & 2.112 & 0.959 \\
Perception of controllability & Pre-test & -1.833 & 0.924 & 0.132 \\
& Post-test & -1.500 & 1.336 & 0.507 \\
Perception of behavior & Follow up & -1.167 & 1.271 & 0.633 \\
justification & Pre-test & 0.083 & 0.596 & 0.989 \\
& Post-test & -1.417 & 0.807 & 0.200 \\
\hline
\end{tabular}

According to Table 1, the difference between the mean group of training in emotional regulation and mindfulness training is found in the pretest phase in the variables total score of cognitive flexibility is ($1.333)$ and the components perception of different options (0.417), perception of controllability (-1.833) and perception of behavior justification $(0.083)$ are not significant $(\mathrm{p}<0.05)$. This finding shows that in the pre-test stage there is no significant difference between the emotion regulation and mindfulness training group and that the groups are homogeneous. The average difference between the group of emotional regulation training with mindfulness training in the post-test stage in the variables total score of cognitive flexibility (-5) and the components perception of various options (-2.803), perception of controllability (-1.500) and perception of behavior justification $(-1.417)$ was not significant $(\mathrm{p}<0.05)$. This finding shows that there is no significant difference between the emotional regulation training group and the post-test mindfulness training for these variables.

The difference between the mean value of the emotional regulation training group with mindfulness training in the follow-up phase in the variables of the total score of cognitive flexibility (-1.667) and the components of the perception of different options ($0.583)$, perception of controllability (-1.167) and perception of behavior justification $(-0.083)$ were not significant $(\mathrm{p}>0.05)$. This finding shows that there is 
no significant difference between the emotional regulation and mindfulness training groups in the post-treatment phase.

According to Table 2, the difference between the mean value of the emotional regulation training group and the mindfulness training in the pretest stage in the variables proximity (1.667), dependency (0.333), conflict (1.417) and parent-child relationship (-0.750) is not significant $(\mathrm{p}>0.05)$. This finding shows that in the pre-test phase there is no significant difference between the emotional regulation training group and the mindfulness training and that the groups are homogeneous. The difference between the mean of emotional regulation training group with mindfulness training in the post-test stage in variables proximity (1.750), dependency (-0.750), conflict (0.833) and parent-child relationship (4.833) were not significant $(p>0.05)$. This finding shows that there is no significant difference between the emotional regulation training group and the mindfulness training group in post-test stage for these variables.

The difference between the mean value of the training group of emotional regulation and mindfulness training group in the follow up phase is significant $(\mathrm{p}<0.01)$ in the proximity variable $(2.917)$. This finding shows that the average of the emotion regulation training group in the follow up phase is significantly higher than the average of the mindfulness training group. The difference between the mean value of the emotional regulation training group with mindfulness training group in the follow up phase was not significant in the variables dependency (-0.250), conflict (0.250) and parentchild relationship (6.583) $(\mathrm{p}>0.05)$. This finding shows that there is no significant difference between the emotional regulation and mindfulness training groups in the follow up phase.

Table 2. Results of the comparison of the mean values of the test groups in the three pretest, posttest and follow-up stages in the father-child interaction of mothers with children with mild intellectual disabilities

\begin{tabular}{cccccc}
\hline \multicolumn{2}{c}{ Variable } & Measurement step & Mean difference with control group & Standard error (SE) & P-Value \\
\hline & \multirow{6}{*}{ proximity } & Pre-test & 1.667 & 0.845 & 0.979 \\
& & Post-test & 1.750 & 1.021 & 0.215 \\
& & Follow up & 2.917 & 0.795 & 0.002 \\
& & Pre-test & 0.333 & 0.909 & 0.929 \\
& dependency & Post-test & -0.750 & 0.791 & 0.737 \\
Child-parent & & Follow up & -0.250 & 2.412 & 0.939 \\
interaction & & Pre-test & 1.417 & 2.339 & 0.828 \\
& conflict & Post-test & 0.833 & 2.113 & 0.933 \\
& & Follow up & -0.250 & 1.648 & 0.992 \\
& & Pre-test & -0.750 & 3.210 & 0.301 \\
& parent-child & Post-test & 4.833 & 3.454 & 0.153 \\
\hline
\end{tabular}

\section{Conclusion}

The aim of this study was to compare the effectiveness of emotional regulation and mindfulness training in cognitive flexibility and parent-child interaction in mothers of children with mild intellectual disabilities. The results of the mixed analysis of variance showed that there were no significant differences between the effectiveness of emotion regulation training and mindfulness in improving parent-child interactions in mothers of children with children with intellectual disabilities in the post-test stage. No study related to the results of this section was found while studying the research background. Explaining the lack of differences in the effectiveness of emotion regulation and mindfulness training to improve the areas of proximity, dependency, conflict, and the overall positive relationship of parent-child interactions in the posttest phase, and no differences in the effectiveness of emotional regulation and mindfulness training to improve the area of dependency, conflicts and overall positive relationship of parent-child interactions in the follow up phase of mothers with children with mild intellectual disabilities. It can be said that conscious parenting is a framework through which parents create intentionally awareness about their moment with their children. This is done by enhancing the ability to actively listen when dealing 
with children, promoting emotional awareness and self-regulation in their upbringing, as well as empathetic and critical acceptance of parental interactions (Duncan et al., 2009).

Given that mindfulness training and emotional regulation exert their effect on the interaction between parents and children through their mediators, it seems logical that both interventions methods improve the parent-child interactions and its component equally. Also while explaining the greater effectiveness of emotion regulation training in the area of parent-child interaction among mothers of children with children with mild intellectual disabilities in the post-treatment phase, it can be argued that emotional regulation strategies require more time than the mindfulness strategies to consolidate their full effectiveness, and the more and longer the exercises for emotional regulation are done, the more favorable effects will have on the parent-child interaction in the intimate area, which lasts based on positive emotions and feelings. To confirm this, Rutherford et al. (2015) believe that the regulation of emotions, like the ability to influence one's experience and expression, is a complex skill that develops over time and its effects become more and more manifested.
Of the limitations of the present study, it can be said that due to administrative problems in determining the sample, a random selection was not possible and only a random placement was performed. This study was carried out in mothers with children with intellectual disabilities so its generalization on mothers with child with other disabilities is limited. Physicians and pediatricians with special needs and their parents are encouraged to use both emotional regulation training and mindfulness training as complementary therapies in the form of workshops and group intervention sessions to benefit from cognitive flexibility and parent-to-child interaction of mothers with children with mild mental disabilities.

\section{Ethical Considerations}

Compliance with ethical guidelines: Conscious consent was obtained from all participants. This research has been registered in the National Ethics Committee with the ID IR.IAU.RASHT.REC.1399.009

Funding: This research is done in the form of a doctoral dissertation without financial support.

Authors' contribution: All authors participated in the drafting of the article and approved the final version.

Conflict of interest: The authors do not express any conflict of interest in this study.

Acknowledgments: The authors consider it necessary to thank all the participants in the research. 


\section{اثربخشى آموزش نظم جويى هيجانى در مقايسه با آموزش ذهن آحاهى بر انعطاف يذيرى شناختى و تعامل والد - فرزند

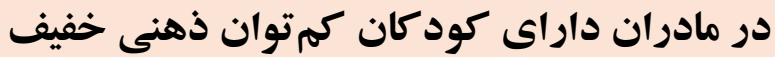

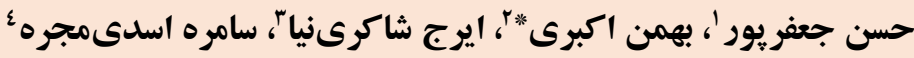

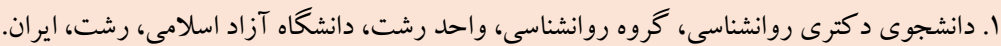

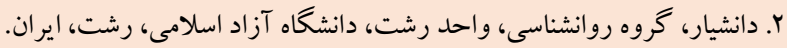

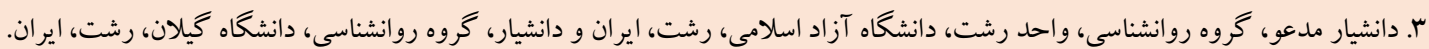

F. استاديار، كروه روانشناسى، واحد رشت، دانشخاه آزاد اسلامى، رشت، ايران.

\begin{tabular}{|c|c|}
\hline جـيده & 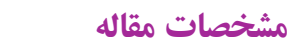 \\
\hline زمينه: بررسى ييشينه نشان مىدهد كه آموزش نظم جويى هيجانى و ذهن آكاهى هر يكك منجر به ارتقاء انعطاف يذيرى شناختى و تعامل والد & 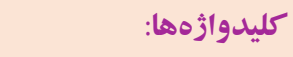 \\
\hline - فرزند شدهاند؛ اما هنوز مشخص نيست كدام يكك از اين مداخلات مى تواند در طول زمان اثربخشى بيشترى داشته باشند. & 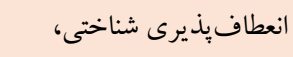 \\
\hline هدف: يُروهش حاضر با هدف مقايسه اثربخشى آموزش نظم جويى هيجانى و ذهن آكاهى بر انعطافيذيرى شناختى و تعامل والد - فرزند & 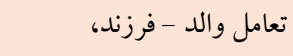 \\
\hline در مادران داراى كود كان مبتلا به كمتوانى ذهنى خفيف انجام شد. & 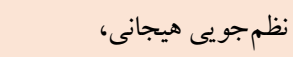 \\
\hline 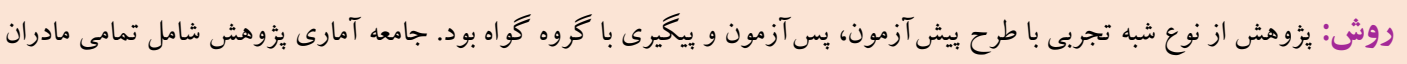 & ذهن Tكاهى، \\
\hline 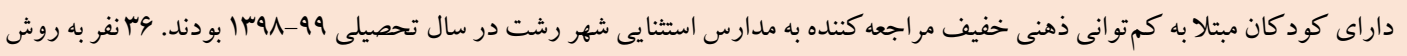 & 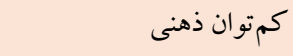 \\
\hline در دسترس انتخاب و به صورت تصادفى در سه گروه rا نفرى قرارگرفتند. گروههاى آزمايش تحت آموزش نظمجويى هيجانى & \\
\hline 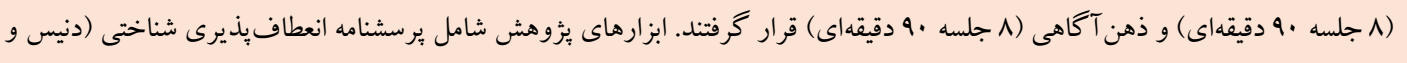 & \\
\hline وندروال، · · ·r) و مقياس رابطه والد - فرزند (ييانتا، 199F) بودند. تحليل دادهها با روش تحليل واريانس مختلط انجام شد. & \\
\hline يافته ها: آموزش نظمجويى هيجانى و ذهن آكاهى بر بهبود انعطاف بذذيرى شناختى و تعامل والد - فرزند و مؤلفههاى آنها در مراحل & \\
\hline 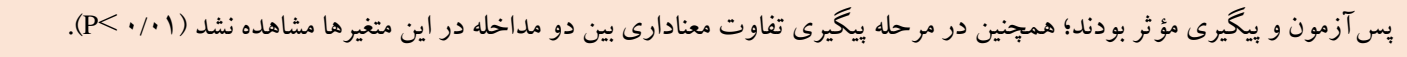 & \\
\hline نتيجه كيرى: با توجه به نتايج مىتوان كفت آموزش نظمجويى هيجانى و ذهن آكاهى با ارتقاى بازسازى هيجانى، كاهش بردازش خود & \\
\hline ارجاعى منفى و افزايش تو انايى انجام رفتارهاى هدفمند، آكاهى از تجربيات لحظه حاضر و بر گرداندن توجه بر سيستم شناختى و يردازش & 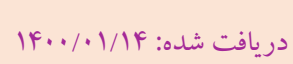 \\
\hline كار آمدتر اطلاعات، در نهايت باعث بهبود انعطافيذيرى شناختى و تعامل والد - فرزند مادران داراى كود كان مبتلا به كمتوانى ذهنى خفيف & 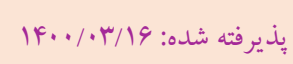 \\
\hline شدند. & 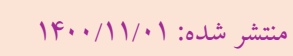 \\
\hline
\end{tabular}

* نويسنده مسئول: بهمن اكبرى، دانشيار، گروه روانشناسى، واحد رشت، دانشكاه آزاد اسلامى، رشت، ايران. راياناه: bakbari44@yahoo.com 
تعامل والد - فرزند † آسيب ديده نيز از جمله منابع مشكلات والدگرى،

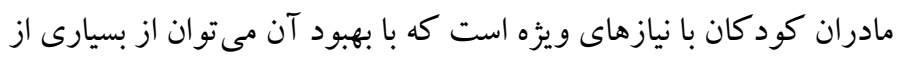
مشكلات ناشى از عدم ارتباط مناسب بين والدين و اين قبيل كود كان ونان

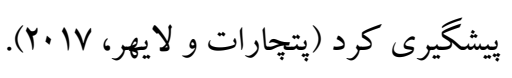

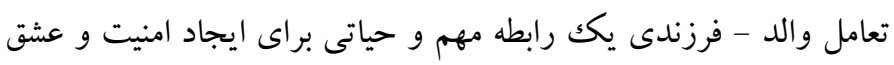

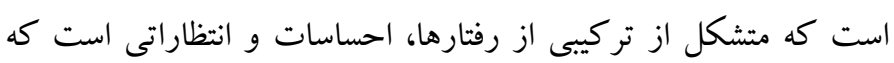

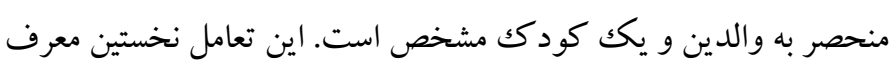

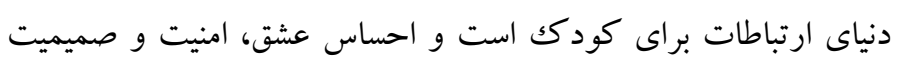

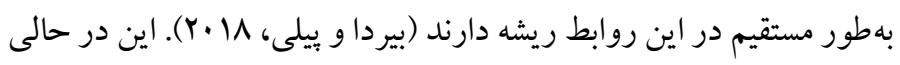

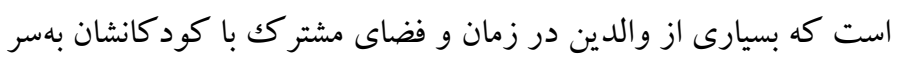

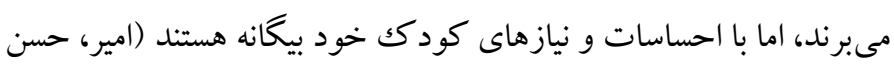

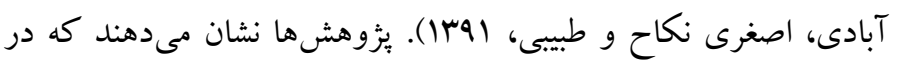

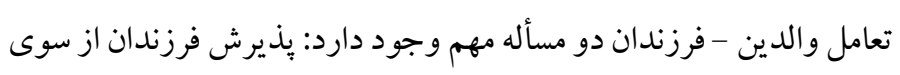
والدين و مهار فرزندان توسط والدين، كه هر دوى اين موارد مى تو اند تعيين كننده نوع رفتار فرزندان و بازتاب آن در والدين باشد (حسين خانزاده،

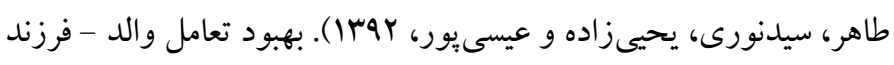

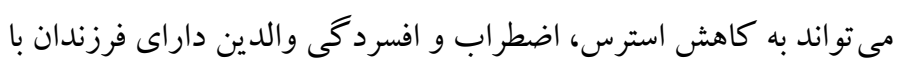

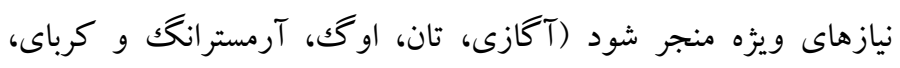

. (Y.IV

يُزوششها راهكارهاى متفاوتى را جهت بهبود مشكلات شناختى، رفتارى

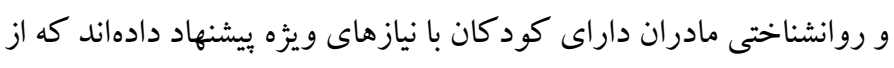
آن جمله آموزش نظم جويى هيجانى (متين، اخوانغلامى و احمدى أنى،

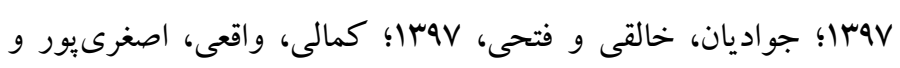

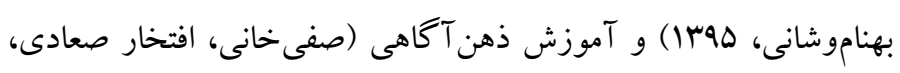

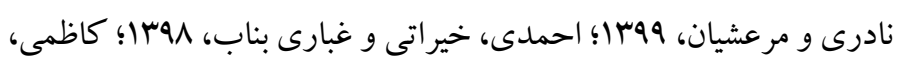

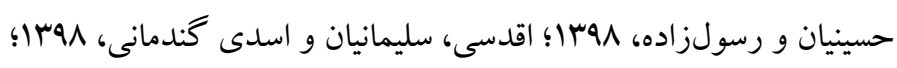

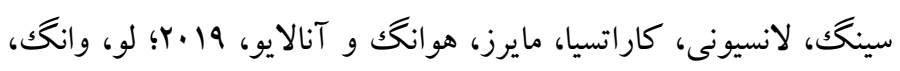

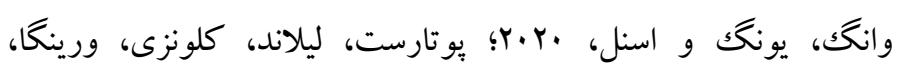

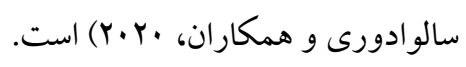

2. Parent-child interaction dolقo

كودكك مبتلا به كمتوان ذهنى تنش بسيارى را در اعضاى خانو اده بهويزه

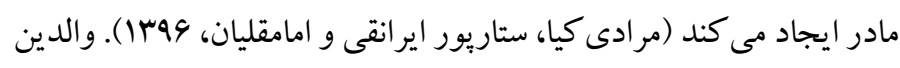

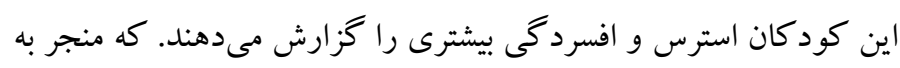

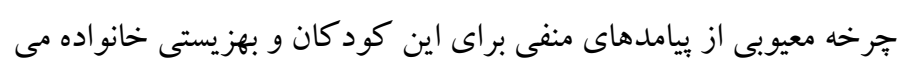

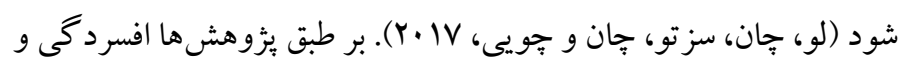

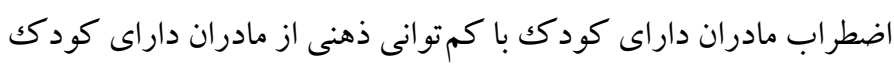

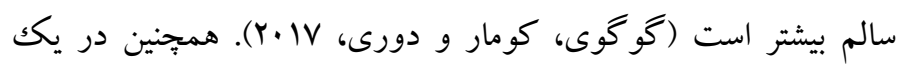

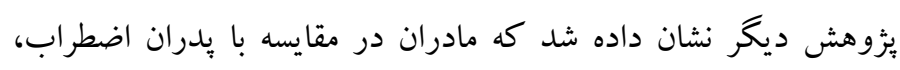
افسردگى و استرس بيشترى را تجربه مى كنند (عظيم، دو گار، شاه، جمما،

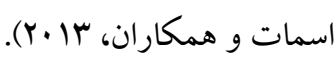

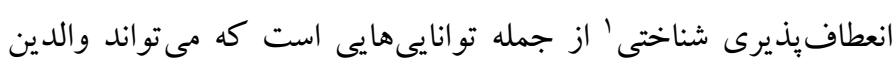

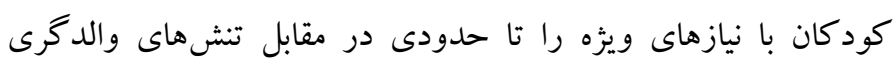

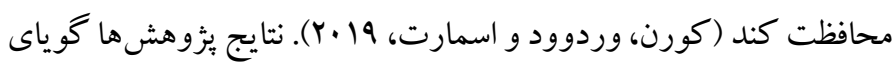

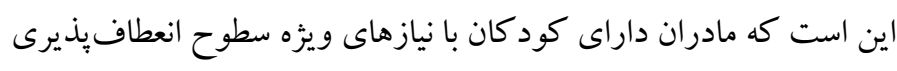

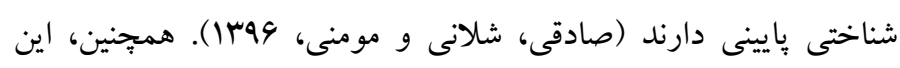

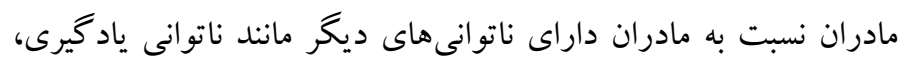

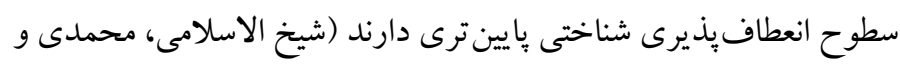

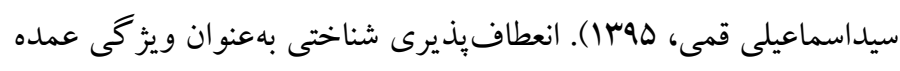

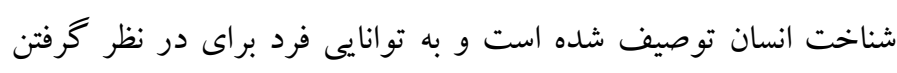
همزمان بازنمايىهاى متناقضى از يك شىء يا يكك رويداد اشاره دارد

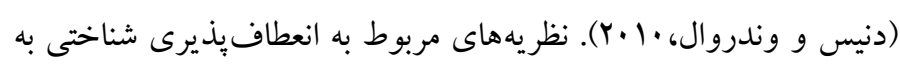
دو دسته تقسيم مىشوند موج اول تحقيقات در زمينه انعطافيذيرى

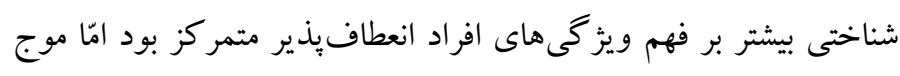

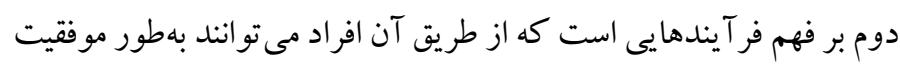

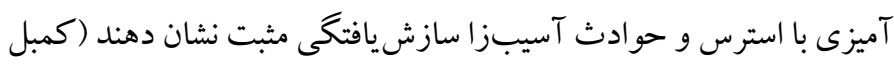

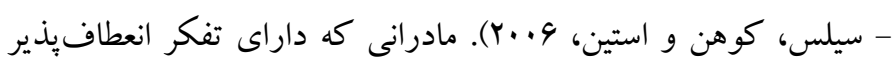

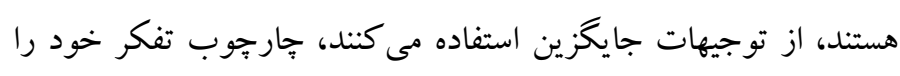

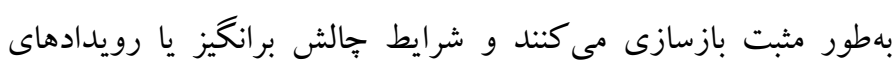

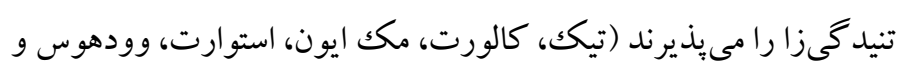

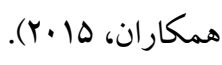

1. cognitive flexibility 


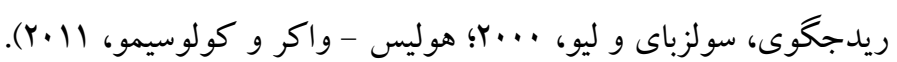

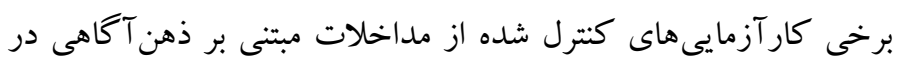

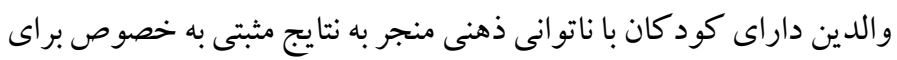

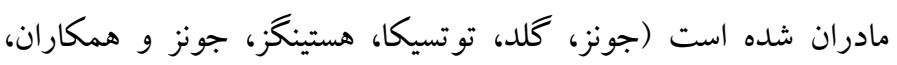

. ( r. I

در اين راستا، مطالعات متعدد نشان دهنده اثرات مثبت آموزش ذهن آكاهى

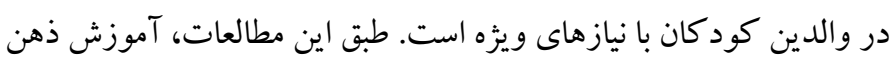
آكاهى بر ارتقاء معنويت و يردازش هيجانى مادران داراى دانش آموزان

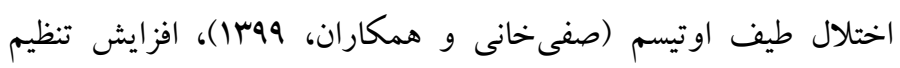
شناختى هيجان و انعطاف يذيرى شناختى مادران كود كان با ناتوانىهاى

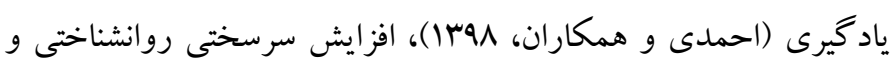
كاهش نشخوار فكرى مادران داراى دانش آموزان با ناتوانىهاى هماى يادكيرى (كاظمى و همكاران،

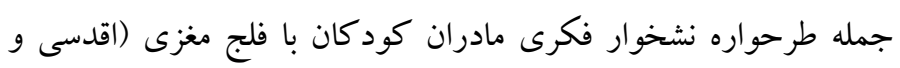

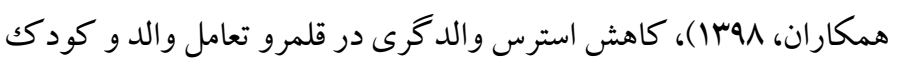

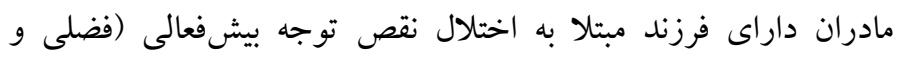

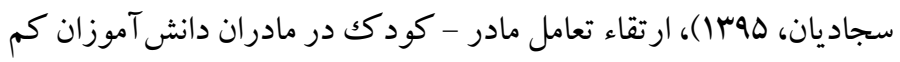

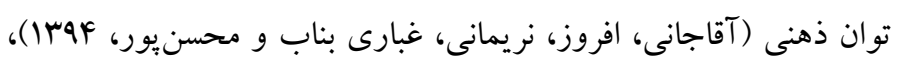

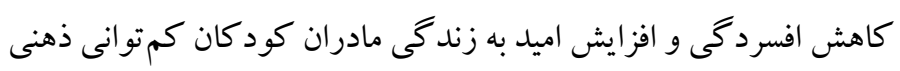

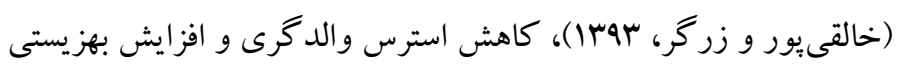

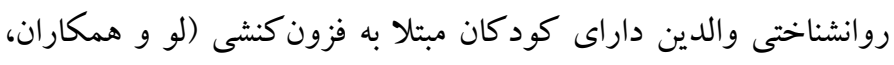

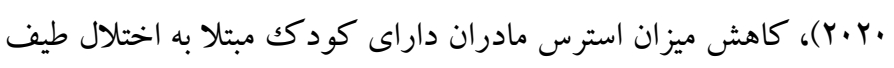

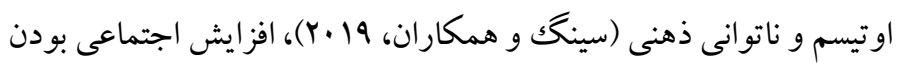

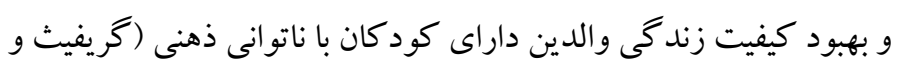

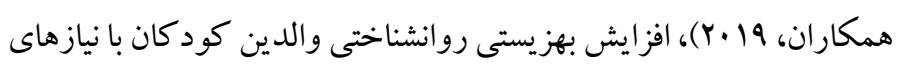

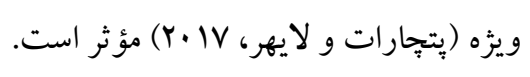

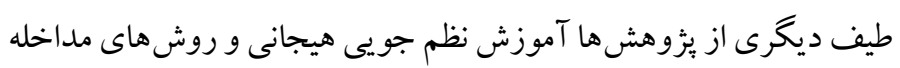

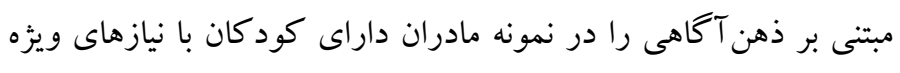

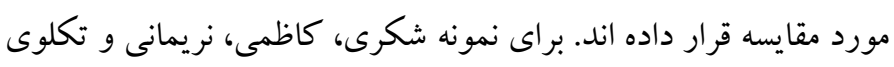

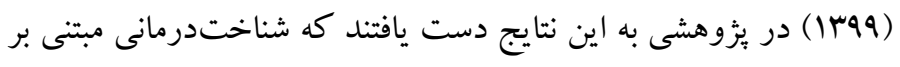

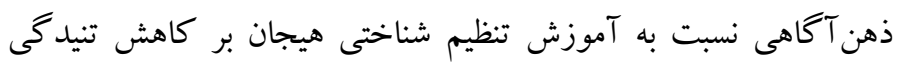

${ }^{2}$. Mindfulness-Based Cognitive Therapy (MBCT)
آموزش نظم جويى هيجانى' شامل آموزش راهبردهايى است كه منجر به

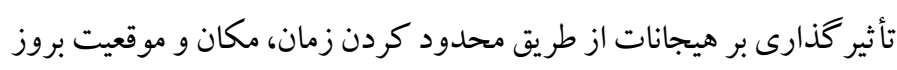
آنها است كه شامل نظم جويى هيجانهاى مثبت و منفى مى شود (مككرى مئن

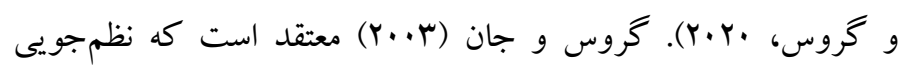

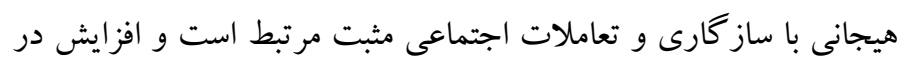

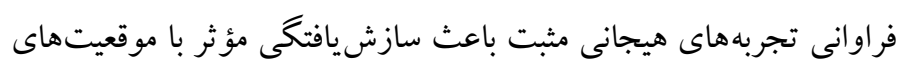

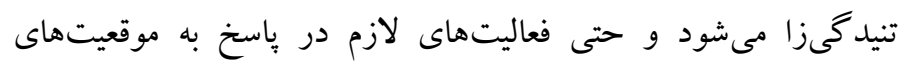

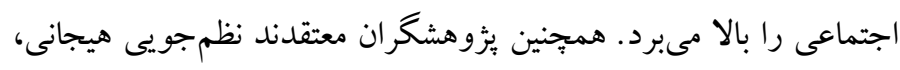
بهعنوان توانايى تأثير گذارى بر تجربه و ابراز هيجانات فرد، يك مهن مهارت بيجيده است كه در طول زندكى تكامل مى يابد (رادرفورد، واليس، لارنت

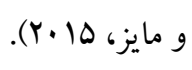

مطالعات متعدد نشاندهنده اثرات مثبت آموزش نظم جويى هيجانى بر بهبود متغيرهاى مختلف روانشناختى در نمونه والدين كود كان با نيازهاى ويثه

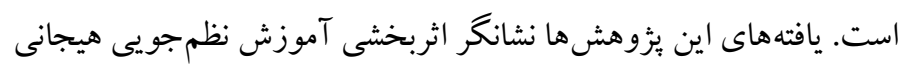

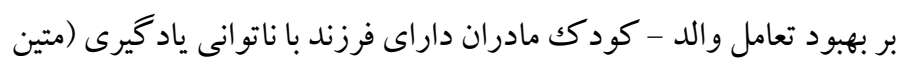

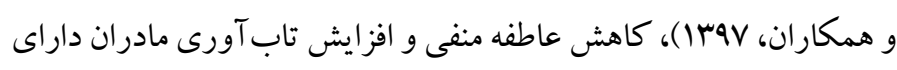

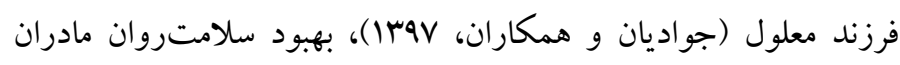

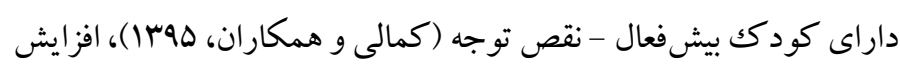
سلامتروان مادران داراى فرزندان مبتلا به اختلالات روانى (آبيار،

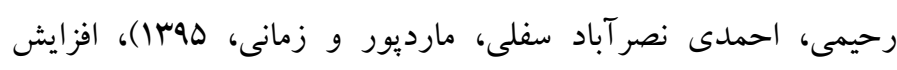

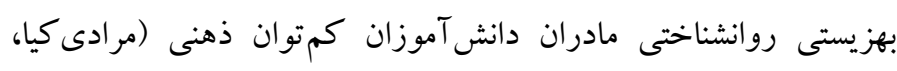
ارجمندنيا و غبارى بناب، هه؟r) و كاهش نشخوار فكرى (كرمى، شريفى، نيك خواه و غضنفرى، لوجما) است.

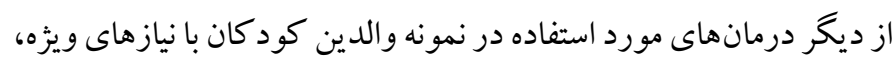

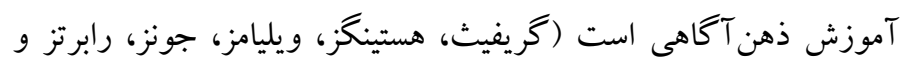

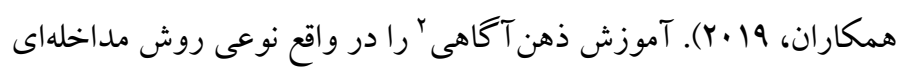

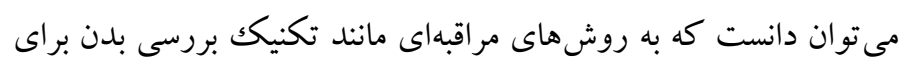

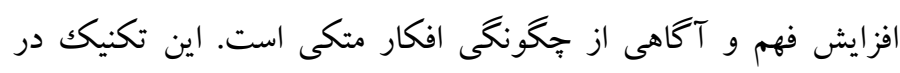
راستاى ارتقاء آكاهى بدون قضاوت لحظه به لحظه، توجه به لحظه اهنه حاضر،

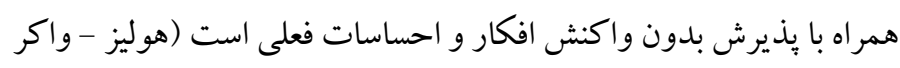

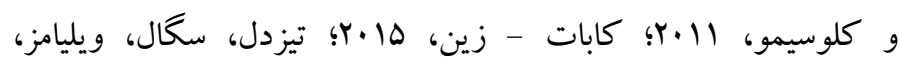

1. Emotional regulation training 
ماهه سه گروهى بود. جامعه آمارى إثزوهش شامل تمامى مادران داراى كود كان مبتلا به كم توانى ذهنى خفيف مراجعه كننده به مدارس استثنايى

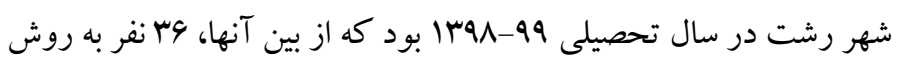
در دسترس انتخاب و به صورت تصادفى در سه گروه (دو گروه آزمايش و يك گروه گواه) قرار گرفنتد.

\section{ب) ابزار}

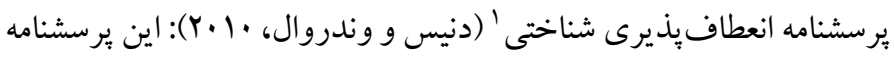

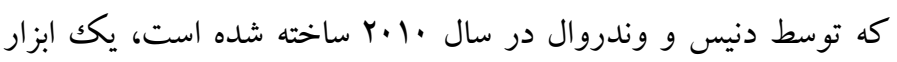

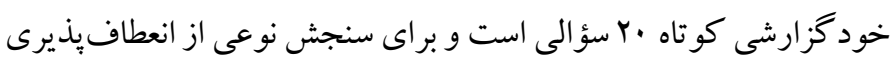

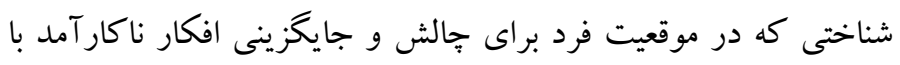

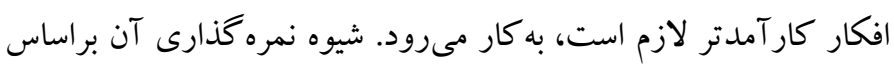

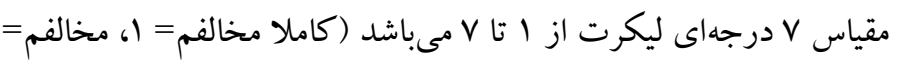

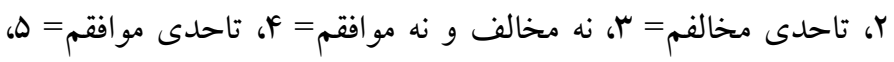

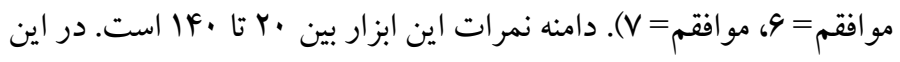

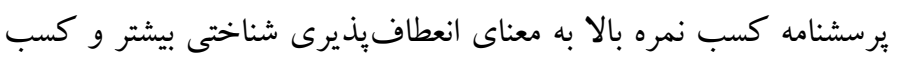

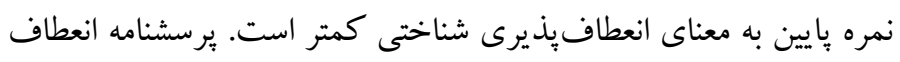

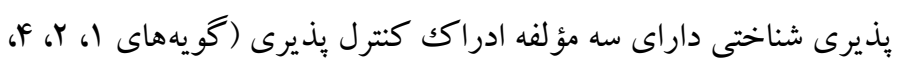

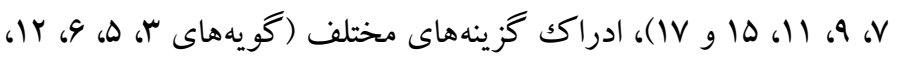

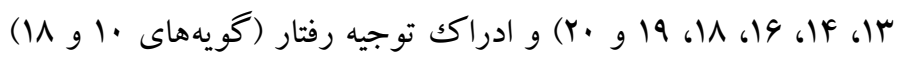

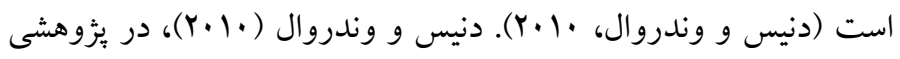

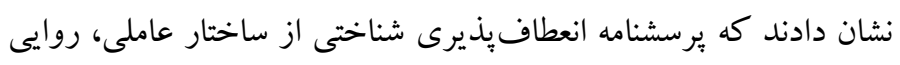

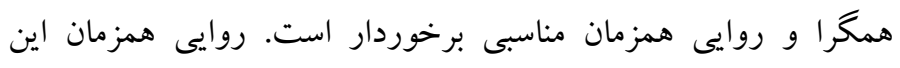

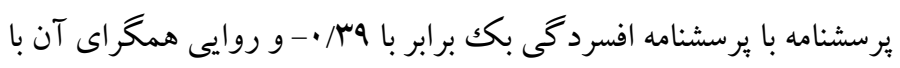

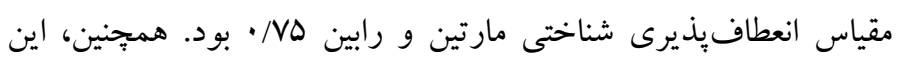
يثزوهشخران جهت سنجش يايايى اين برسشنامه از روش آزمون - باز آزمون

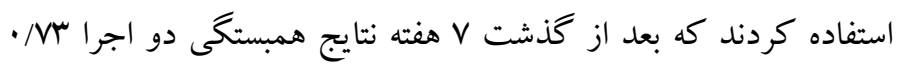

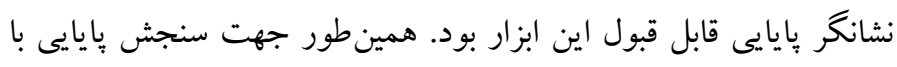

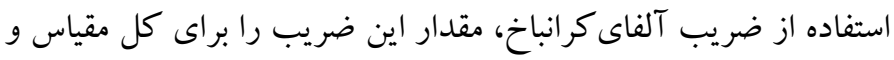

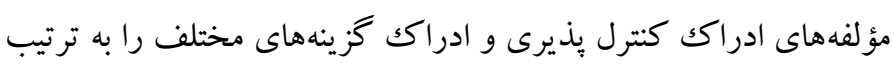

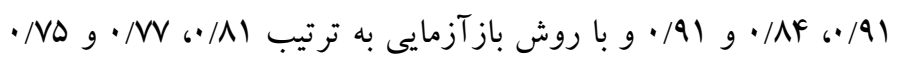

والدينى مادران كود كان يرخاشخر مؤثرتر است. در مقابل بيرامى، هاشمى،

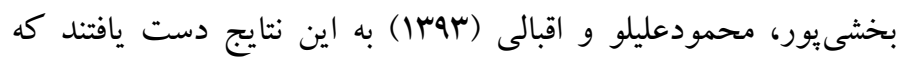

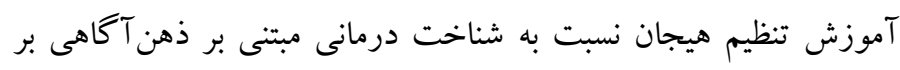

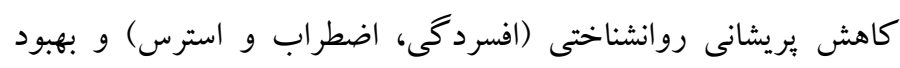
راهبردهاى شناختى تنظيم هيجان مادران كود كان عقبمانده ذهنى مؤثرتر

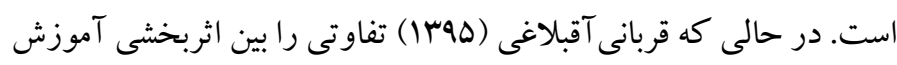
ذهن آكاهى و نظمجويى هيجانى بر بهبود كيفيت زندكى و تاب آورى درى

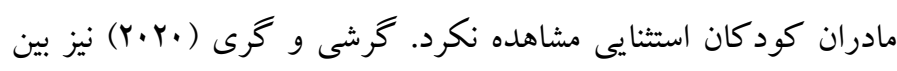
اثربخشى آموزش نظمجويى هيجانى و ذهن آكاهى بر كاهش خش خشونت

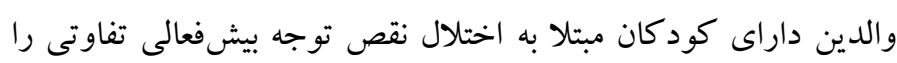
مشاهده نكردند.

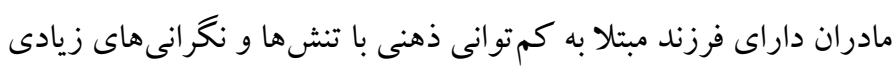

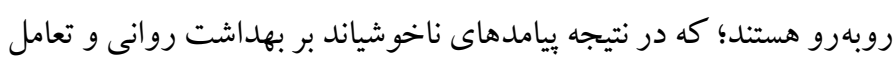

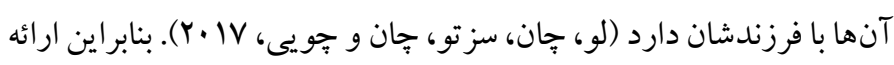

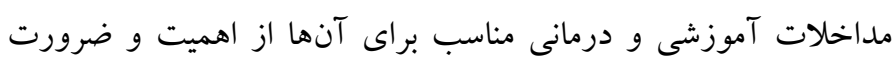

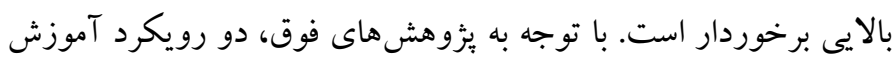

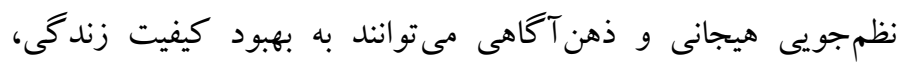
انعطاف يذيرى شناختى و كاهش تنيدگى اين مادران تأثير داشته باشند. اما

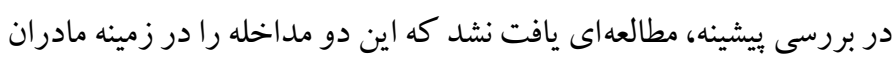

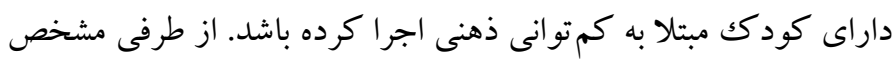

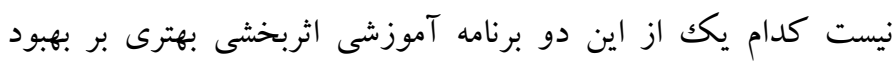

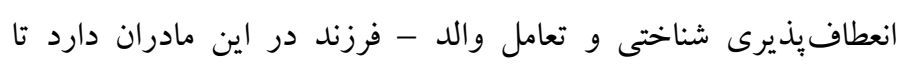

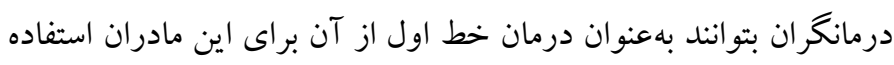

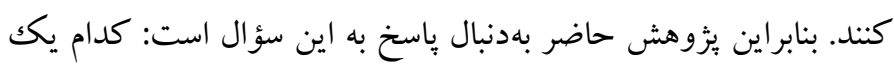

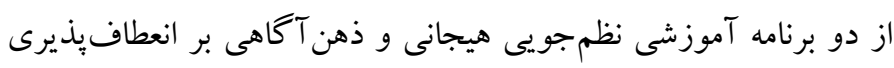

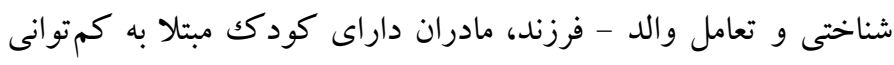

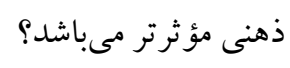

روش

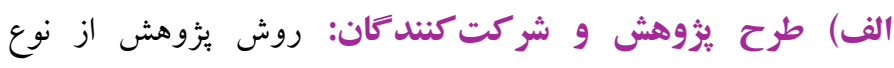

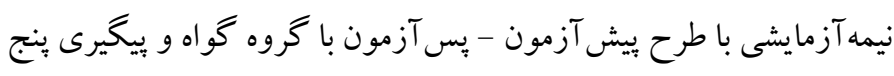

1. The cognitive flexibility inventory (CFI) 
Frar). دريكسول و بيانتا (Y) (Y) در بثزوهشى جهت سنجش بايايى اين

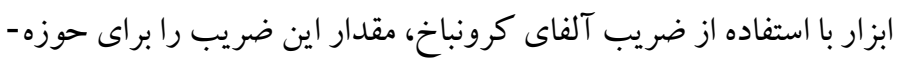

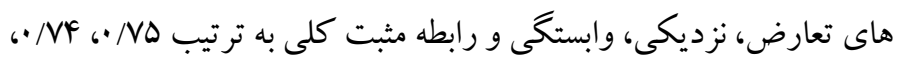

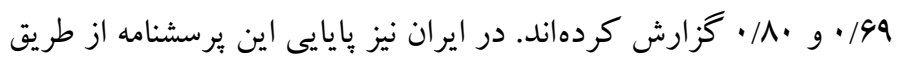

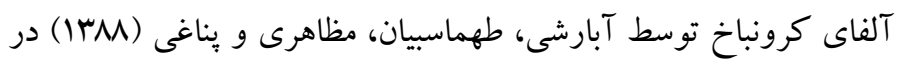

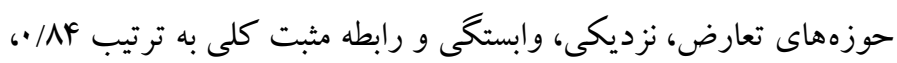

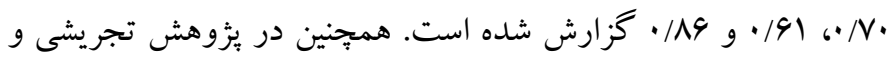

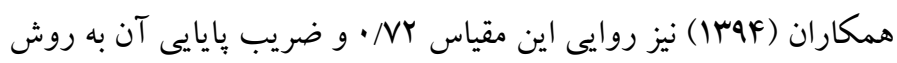

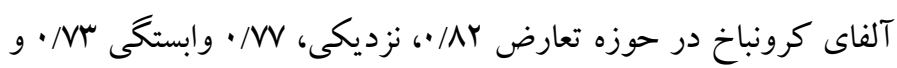
رابطه مثبت كلى NF/ به دست آمد. در بثزوهش حاضر نيز ضريب آلفاى

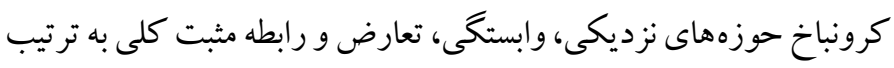

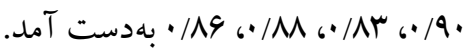

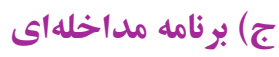
آموزش نظمجويى هيجان: برنامه آموزش نظمجهويى هيجانى براساس

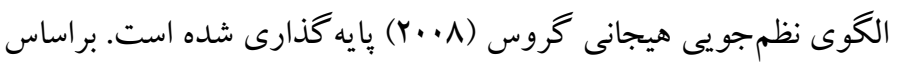

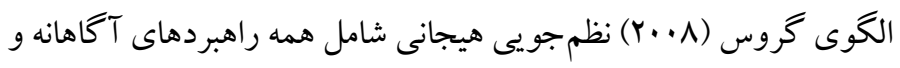
غير آكاهانهاى است كه براى افزايش، حفظ و كاهش مؤلفههاى هيجانى، رفتارى و شناختى يكك باسخ هيجانى به كار برده مىشود. اين برنامه

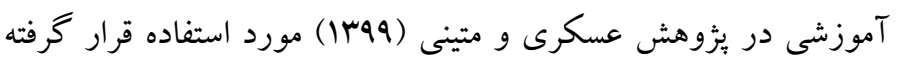

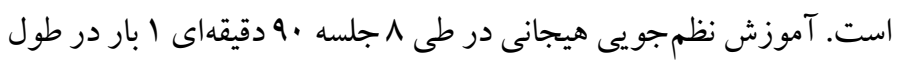

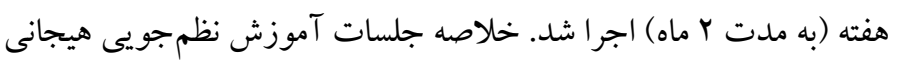
در جدول ا ارائه شده است. آموزش ذهن آكاهى: آموزش ذهن آكاهى براساس الكوى كابات - زين

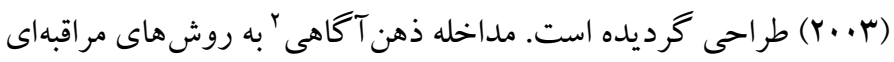

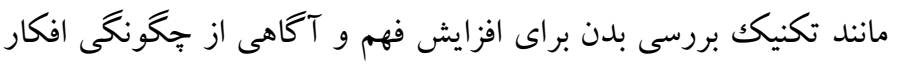

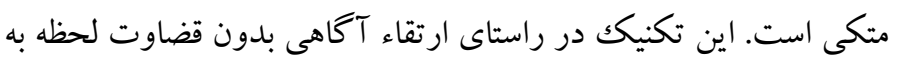

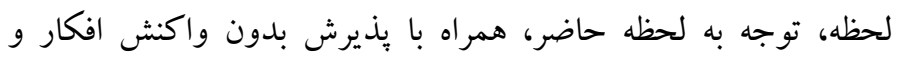

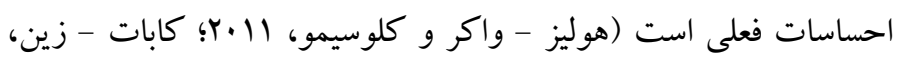

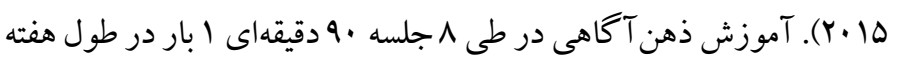

2. Mindfulness-Based Cognitive Therapy (MBCT)
بهدست آوردند. در ايران نيز شاره، فرمانى و سلطانى (F) (Y) اين برسشنامه را هنجاريابى كردند كه بر اين اساس، ضريب پايايى باز آزمايى كل مقياس

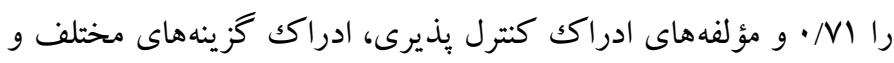

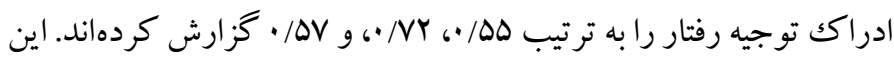

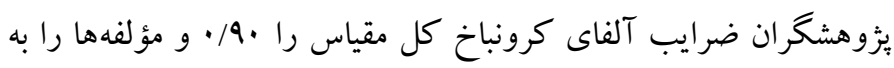

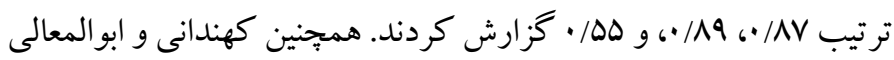

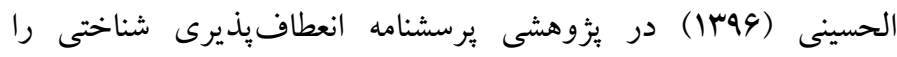

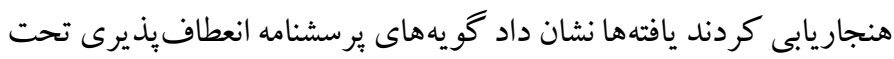

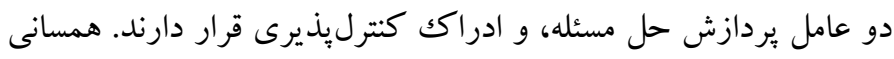

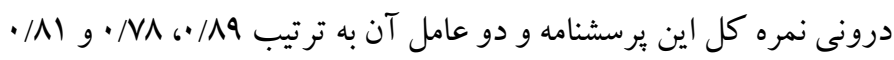

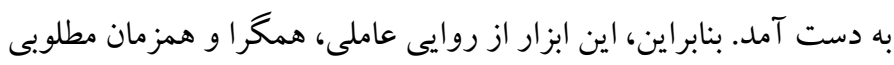

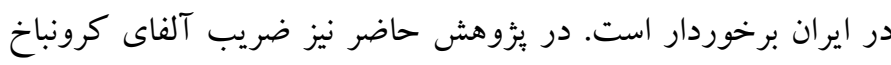

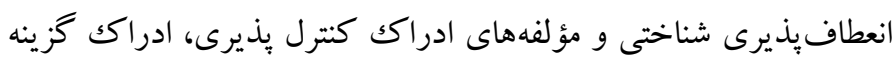

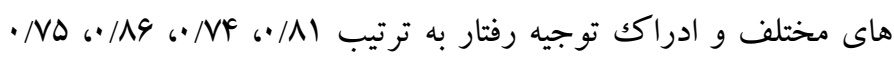

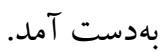

مقياس رابطه والد - فرزند' (ييانتا، 199F): اين مقياس توسط يِانتا در سال

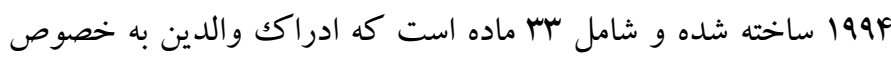

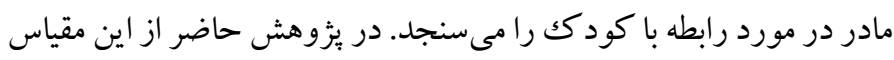
جهت سنجش رابطه مادر - كودكك استفاده شده است. اين مقياس

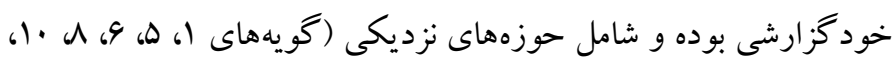

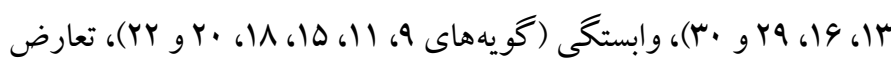

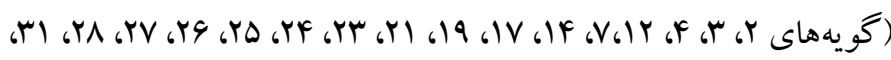
r و و س و و رابطه مثبت كلى (كه همان نمره كل است از مجموع نمر ات ات

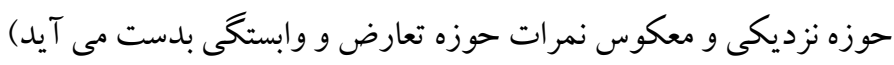

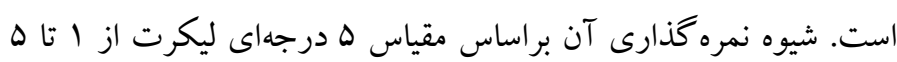

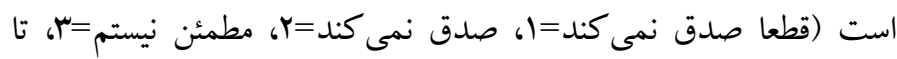

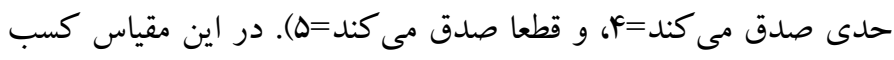

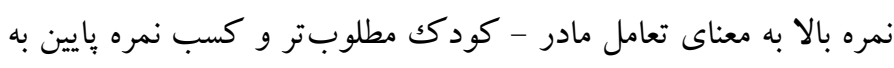

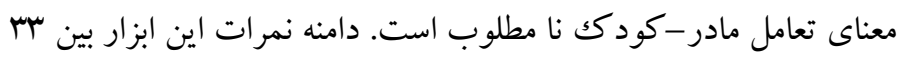
تا 190 است. اين مقياس براى سنجش رابطه والد - كود كك در تمام سنين استفاده مىشود (تجريش، عاشورى، افروز، ارجمنديان و غبارىبناب،

${ }^{1}$. parent child relationship scale (PCRS) 
جدول ا. خلاصه جلسات برنامه آموزش نظمجويى هيجانى (تروس، ^• • ب)

\begin{tabular}{|c|c|c|}
\hline 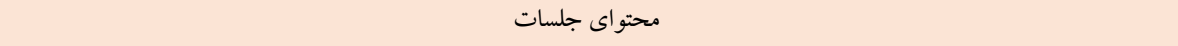 & 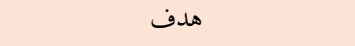 & جلسات \\
\hline 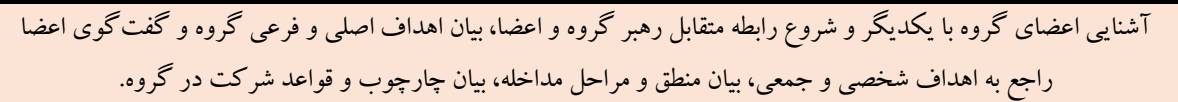 & آشنايى & يكم \\
\hline 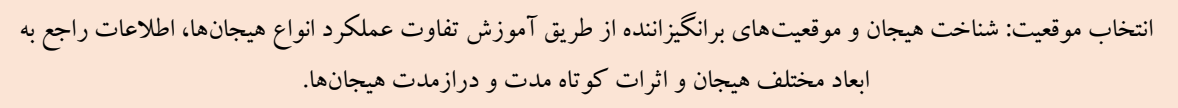 & ارائه آموزش هيجانى & دوم \\
\hline 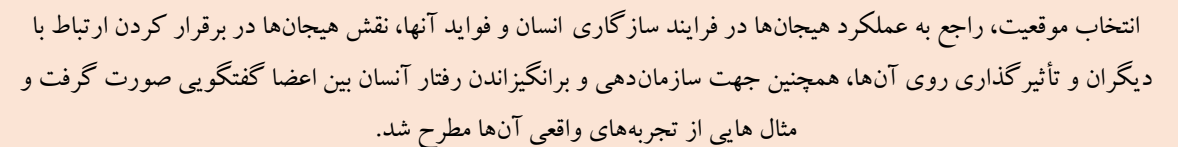 & 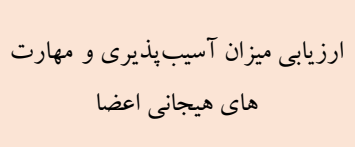 & سوم \\
\hline اصلاح موقعيت، الف) جلو گيرى از انزواى اجتماعى و اجتناب، ب) آموزش راهبرد حل مسئله، ج) آموزش مهارتهاى بين فردى & ايجاد تغيير در موقعيت برانخيز اننده & جهارم \\
\hline گَترش توجه، دستور جلسه: الف) متوقف كردن نشخوار فكرى و نخرانى، ب) آموزش توجه. & تغيير توجه & بنجم \\
\hline ارزيابى شناختى، الف) شناسايى ارزيابىهاى غلط و اثرات آنها روى حالتهاى هيجانى، ب) آموزش راهبرد باز ارزيابى. & تغيير ارزيابى شناختى ت & ششم \\
\hline 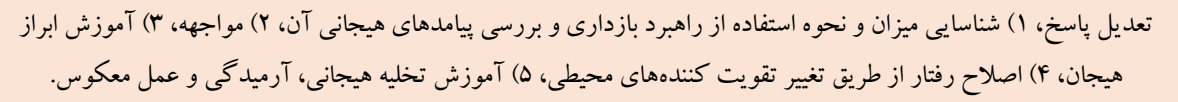 & فيزير ييامدهاى رفتارى و و فيكى هيجان & هفتم \\
\hline 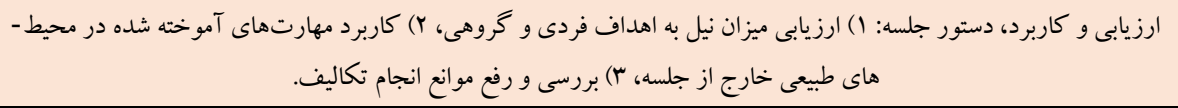 & ارزيابى مجدد و رفع موانع كاربرد & هشتم \\
\hline
\end{tabular}

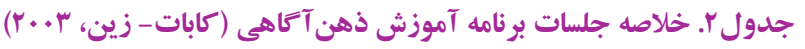

\begin{tabular}{|c|c|c|}
\hline 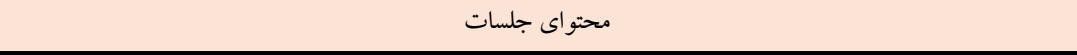 & هدف & 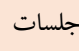 \\
\hline آشنايى با اعضاء گروهو انتظارات آنها، تعيين خط مشى گروه و توضيح بيرامون اختلال ناتوانى ذهنى، تمرين خوردن & هدايت خود كار & يكم \\
\hline ده دقيقه تنفس با ذهن آكاهى، تمرين وارسى بدن. & جالش با مانع & دوم \\
\hline تمرين حر كات كششى همر اه با ذهن آكاهى، تمرين قدم زدن آكاهانه، تمرين وارسى بدن. & ذهن آكاهى در حين حر كت & سوم \\
\hline تمرين ذهن آكاهى نسبت به شنيدن و فكر كردن، داستان ببرهاى گرسنه، تمرين مكث سه دقيقهاى، تمرين وارسى بدن. & 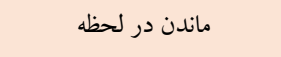 & جهارم \\
\hline 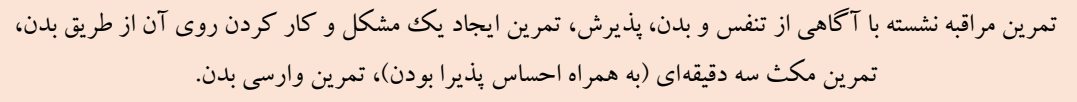 & بذيرش و اجازه دادن & بنجم \\
\hline افكار جانشين، تمرين مكث سه دقيقهاى، تمرين وارسى بدن. & 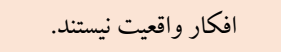 & ششم \\
\hline ارتباط بين خلق و احساسات، جخونه به بهترين نحو از خود مراقبت كنيم، تمرين وارسى بدن. & 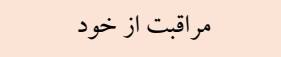 & هفتم \\
\hline تمرين وارسى بدن، بحث يُرامون تداوم تمرينها و برنامهريزى جهت انجام آنها، بررسى مشكلاتى كه مانع از انجام & به كار كيرى آموختها & هشتم \\
\hline
\end{tabular}

برخوردارى مادران از سلامتروان بر اساس مصاحبه بالينى، تشخيص قطعى

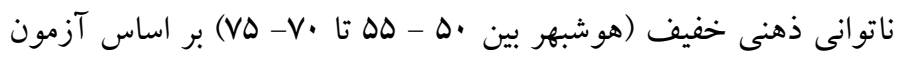

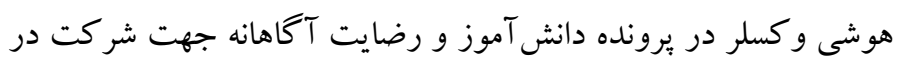

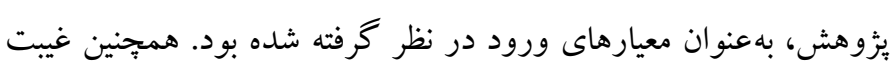
بيش از دو جلسه از مجموع جلسات آموزشى و عدم تكميل برسشنامهها بهنو ان معيارهاى خروج در نظر گرفته شده بود.
د) ورش اجرا جهت اجراى يُزوهش، بِ إز دريافت معرفىنامه از معاونت يُزوهشى

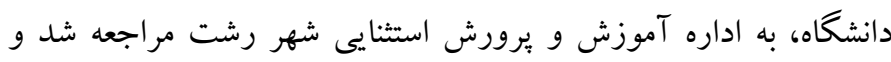

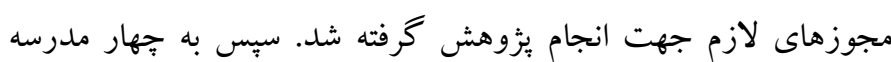

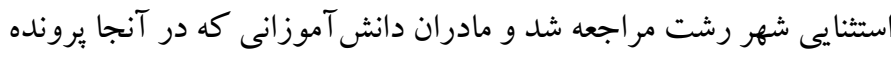

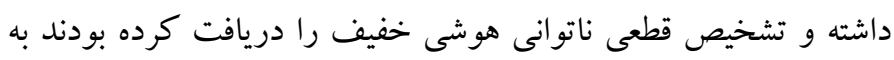
صورت در دسترس بر اساس ملاككهاى ورود به ئزوهش انتخاب شدند. 
معنى دارى متفاوت است. بنابراين بيش فرض كرويت رعايت نمىشود. تخطى از ييشفرض كرويت باعث مى شود آماره F تحليل واريانس دقيق ترسيق

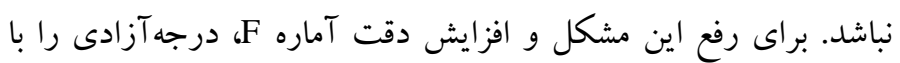
استفاده از دو روش گرين هاوس - گيسر و هاين - فلت تصحيح مى كنيند. براى اينكه از كدام روش تصحيح استفاده كنيم، استيونس (1999) بيشنهاد

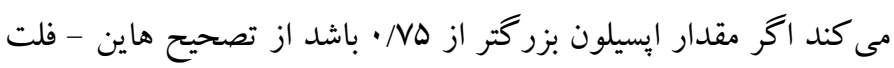

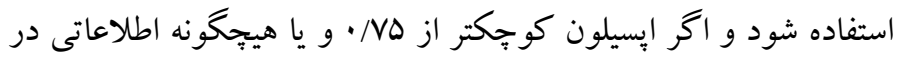
مورد كرويت وجود نداشته باشد از تصحيح گرين هاوس - گ خيسر استفاده

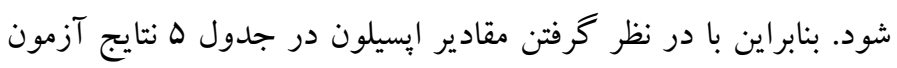

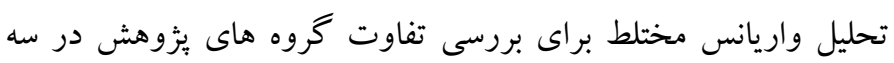

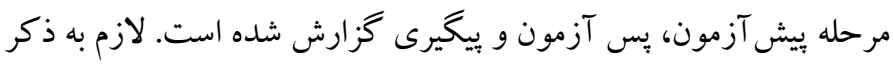

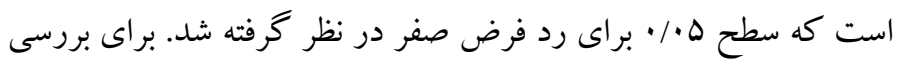

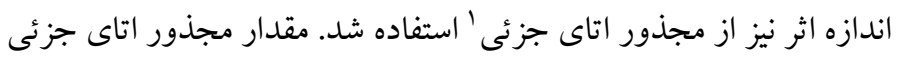

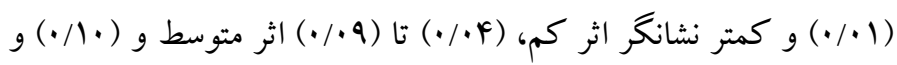

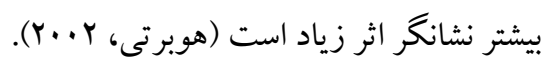

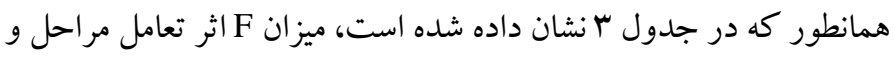

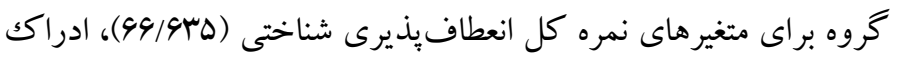

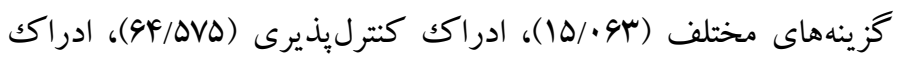

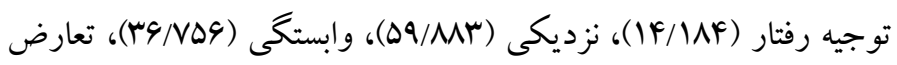

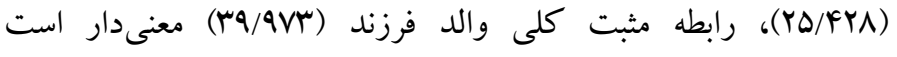

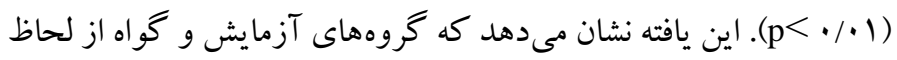

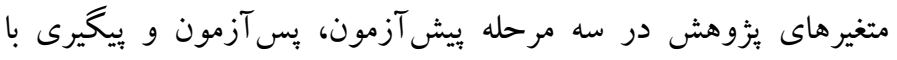
يكديخر تفاوت معنىدارى دارند. همجنين مجذور اتا براى تمامى متغيرها

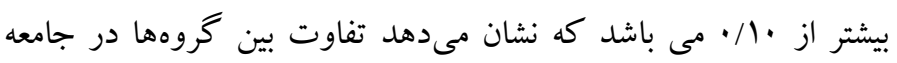
بزرگك و قابل توجه است.

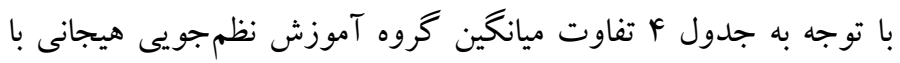
آموزش ذهن آكاهى در مرحله ييش آزمون در متغيرهاى نمره كل انعطاف نهاف

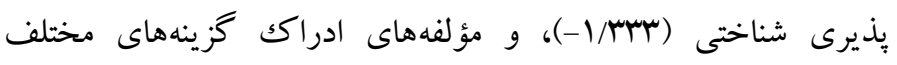

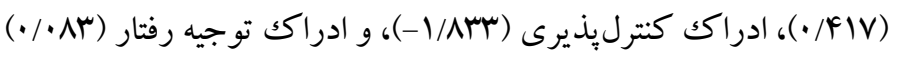

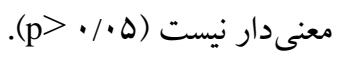

بعد از ارائه توضيحات مقدماتى در خصوص هدف يُزوهش و جلب مشار كت آزمودنى ها و اطمينان بخشى به آزمودنى ها مبنى بر محرمانه ماندن

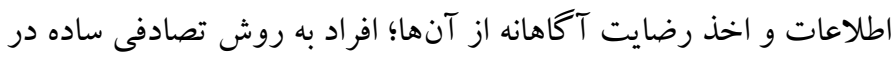

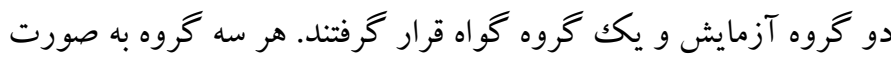

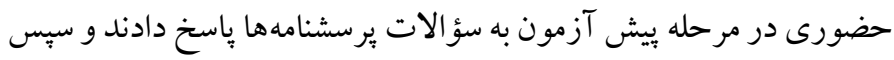

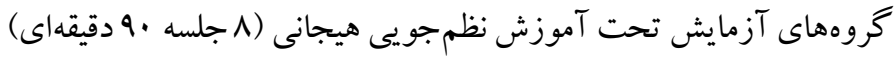

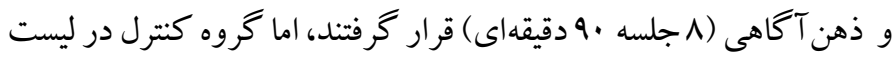
انتظار جهت دريافت مداخله قرار داشت. پِس از اتمام مداخله مجددا

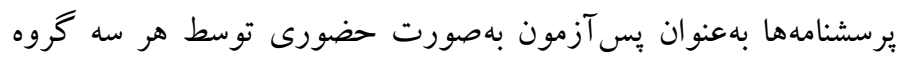

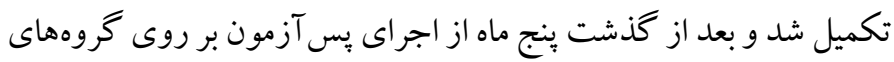

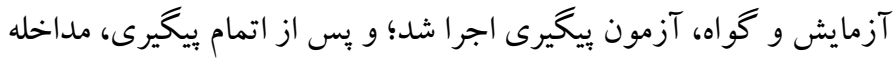

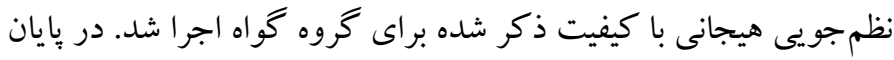

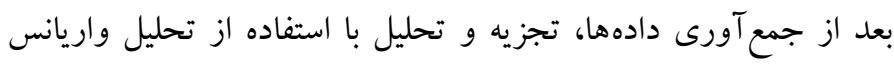
مختلط با كمك نرمافزار SPSS22 انجام شد.

يافته ها در در اين مطالعه 4سنفر در دو گروه مداخله و يك گروه گواه (هر گروه

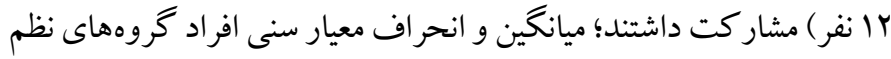
جويى هيجان، ذهن آكاهى و كواه به ترتيب ك و زير دييلم و دييلم بود. همجنين نتايج نشان داد كه توزيع دادهها در متغير هاى

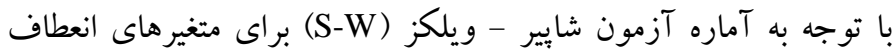
يذيرى شناختى و مؤلفههاى ادراكى گزينههاى مختلف، ادراكى كنترل

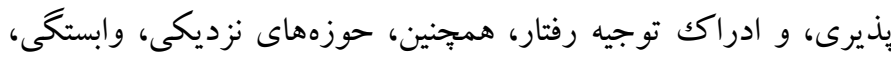

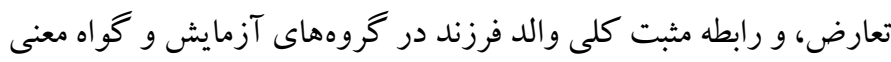

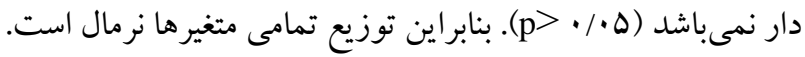

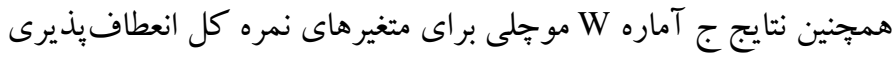

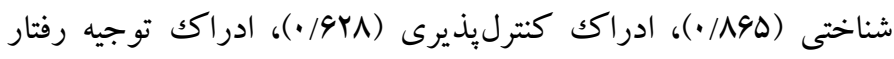

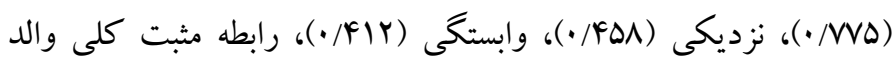

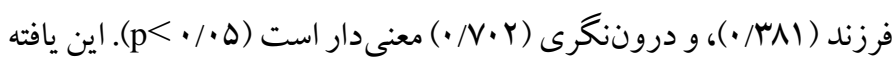
نشان مىدهد كه واريانس تفاوتها در بين سطوح متغير وابسته به صورت

1. Partial eta squared 
جدول ب. نتايج آزمون تحليل واريانس مختلط براى بروسى تفاوت ترووها در متغيرهاى ثئوهش

\begin{tabular}{|c|c|c|c|c|c|c|}
\hline مجذور اتا & $\mathrm{P}$ & F Fاره F F F F & خطا MS & MS & منابع تغييرات & 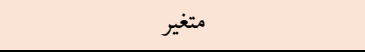 \\
\hline$\cdot / \wedge \Delta$ &.$/ . \cdot 1$ & $Q T / Y M F$ & $\Delta 1 / I V T$ & FVVI/Ir. & كروه ها & \\
\hline$\cdot / 9 Y 1$ & $\cdot / \cdot \cdot 1$ & rAr/orr & $\mid \& / \& 99$ & $\Delta \Delta 9 \cdot / \wedge 9 \wedge$ & 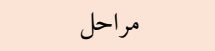 & نمره كل انعطاف يذيرى شناختى \\
\hline$\cdot / A \cdot r$ & $\cdot / \cdot \cdot 1$ & $94 / 940$ & $\mid \& / \& 99$ & Q99/IFA & تعامل مراحل با گروه & \\
\hline$\cdot / D F F$ & $\cdot / \cdot \cdot 1$ & $19 / \mathrm{V} 11$ & rV/rIV & VTr/DAr & كروه ها & \\
\hline - Nar & $\cdot / \cdot 1$ & १९/৭४V & $11 / \cdot r \wedge$ & $11 \cdot r / 194$ & مراحل & ادراكى گزينههاى مختلف \\
\hline$\cdot / F V$ & $\cdot / \cdot \cdot 1$ & $10 / .94$ & $11 / \cdot r \wedge$ & $199 / 111$ & تعامل مراحل با گروه & \\
\hline$\cdot / v \cdot \Lambda$ & $\cdot / \cdot 1$ & rq/arर & $r \cdot / \Lambda r$. & $\wedge r \mathrm{~s} / \mathrm{\Delta .q}$ & كروه ها & \\
\hline $.19 \cdot 4$ & $\cdot / \cdot \cdot 1$ & MIN/DVD & T/TYV & $1 . T N / \triangle \Delta \Lambda$ & 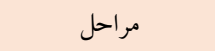 & ادراكك كنترليذيرى \\
\hline •/V99 & $\cdot / \cdot \cdot 1$ & GF/OVD & r/YrV & $r \cdot \Lambda / F \cdot \Lambda$ & تعامل مراحل با گروه & \\
\hline$\cdot / v \Delta Q$ & $\cdot / \cdot \cdot 1$ & $01 / 919$ & T/MFA & Vr. & كروه ها & \\
\hline$\cdot / v \cdot$ & $\cdot / \cdot \cdot 1$ & $\vee \vee / 9 \Lambda 1$ & $r / r \cdot \Lambda$ & TAF/GTO & مراحل & ادراك توجيه رفتار \\
\hline - /AGY & $\cdot / \cdot \cdot 1$ & IF/MAF & $r / r \cdot \Lambda$ & $49 / 91 V$ & تعامل مراحل با گروه & \\
\hline$\cdot / \Delta \Delta r$ & $\cdot / \cdot \cdot 1$ & $r \cdot / r / q$ & $1 \cdot / N 1$ & $r M N / r V$ & كروه ها & \\
\hline$\cdot / A \wedge$ & $\cdot / \cdot \cdot 1$ & $r q \cdot / \cdot v r$ & r/VVq & VYr/GTr & مراحل & نزديكى \\
\hline - VAA & $\cdot / \cdot \cdot 1$ & $\Delta Q / A \mu$ & r/VVQ & $199 / \pi / 9$ & تعامل مراحل با گروه & \\
\hline$\cdot / 9 \cdot Y$ & $\cdot / \cdot 1$ & YF/QFF & $9 / .01$ & rYS/VVA & كروه ها & \\
\hline$\cdot / \mathrm{AV}$ & $\cdot / \cdot \cdot 1$ & rrq/QYq & $r / T / 9$ & DYG/TAV & 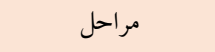 & وابستى \\
\hline.$/ 99$. & $\cdot / \cdot 1$ & rG/VDG & $r / r / 9$ & AD/YOH & تعامل مراحل با گرُوه & تعامل والد فرزند \\
\hline$\cdot /$ raq & $\cdot / \cdot 4$ & D/AYT & $\Lambda F / .9 q$ & $\mathrm{kqN} / \cdot \wedge r$ & كروه ها & 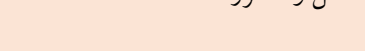 \\
\hline$\cdot / \mathrm{A} 11$ & $\cdot / \cdot 1$ & $|F| / 9 Y 9$ & $\Delta / Y Y V$ & $V F \cdot / \pi T r$ & مراحل & ت تعارض \\
\hline .19 .9 & $\cdot / \cdot \cdot 1$ & rD/FrA & $\Delta / Y Y V$ & $|r Y / Q| V$ & تعامل مراحل با گروه & \\
\hline . NYA &.$/ . .1$ & $F F / r \mid q$ & $9 Y / \Delta I V$ & FIrF/AqA & كروه ها & \\
\hline.$/ 9 \Lambda F$ & $\cdot / \cdot .1$ & $r .99 / \Delta V \Delta$ & $F \Delta / F q$. & AFIFF/FMA & مراحل & رابطه مثبت كلى \\
\hline$\cdot / N \cdot 1$ & $\cdot / \cdot 1$ & $r q / 9 v$ & $f \Delta / f q$. & MNM/raF & تعامل مراحل با گروه & \\
\hline
\end{tabular}

جدول ع. نتايج مقايسه ميانكين كروههاى آزمايش در سه مرحله ييشآزمون، يس آزمون و يِيَيرى در انعطافيذيرى شناختى مادران داراى كودكان مبتلا به كمتوانى ذهنى خفيف

\begin{tabular}{|c|c|c|c|c|}
\hline سطح معنى دارى & خطاى استاندارد بر آورد & تفاوت ميانكين گروه آزمايش با گواه & مرحله & متغير \\
\hline$\cdot 1919$ & $1 / 9 \cdot 4$ & 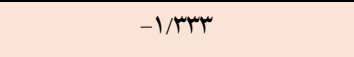 & 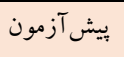 & \\
\hline .1 .94 & $r / r / 9$ & $-\phi$ & 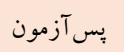 & نمره كل انعطاف يذيرى شناختى \\
\hline$\cdot / V \Delta 9$ & $r /$ rYq & $-1 / 99 \mathrm{~V}$ & ييخيرى & \\
\hline . /QFY & $1 / 499$ & $\cdot / 4 I V$ & ي بيش آزمون & \\
\hline$\cdot / \Delta F I$ & 1/90r & $-r / \cdot \wedge r$ & 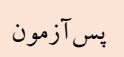 & ادراك كزينهاى مختلف \\
\hline$\cdot / 9 \Delta 9$ & $r / 11 r$ & $-\cdot / \Delta \wedge \mu$ & بيخيرى & \\
\hline 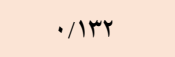 & $\cdot / 9 Y F$ & 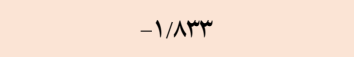 & ميش آزمون & \\
\hline$\cdot / \Delta \cdot V$ & $1 / \pi r 4$ & $-1 / \Delta \ldots$ & 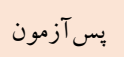 & ادراك كنترليذيرى \\
\hline $.19 \pi r$ & $1 / r V I$ & $-1 / 19 V$ & بيخيرى & \\
\hline$\cdot / 919$ & $\cdot / \Delta 94$ & $\cdot / \wedge r$ & 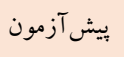 & \\
\hline$\cdot / r \cdot$ & $\cdot / \mathrm{A} \cdot \mathrm{V}$ & $-1 / F \mid V$ & 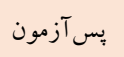 & ادراك توجيه رفتار \\
\hline •/৭9 & $\cdot / N+1$ & $-\cdot / \cdot \wedge r$ & 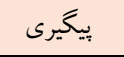 & \\
\hline
\end{tabular}




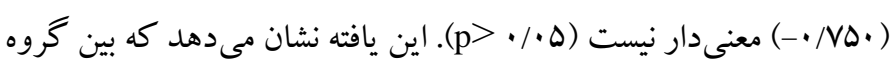
آموزش نظمجويى هيجانى و ذهن آكاهى در مرحله بيش آزمون إنى

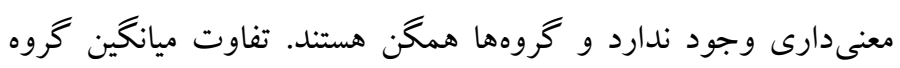

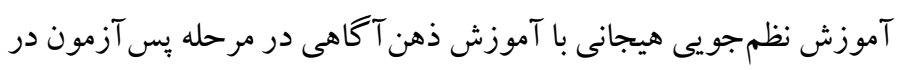

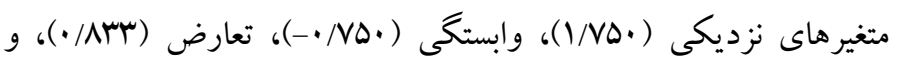

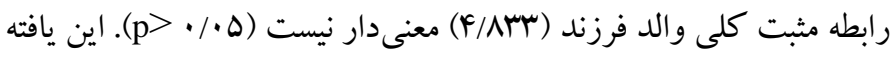
نشان مىدهد بين گروه آموزش نظم جويى هيجانى و ذهن آكاهى در مرحله يس آزمون در اين متغيرها تفاوت معنىدارى وجود ندارد.

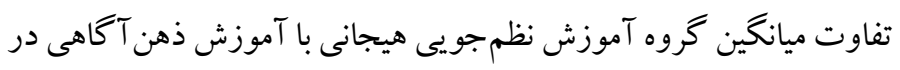

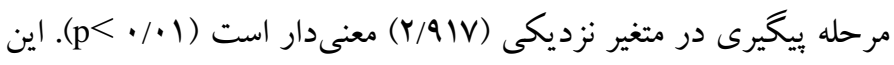
يافته نشان مىدهد كه ميانگين گروه آموزش نظمجويى هيجانى در مرحله

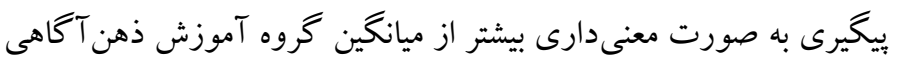
است. تفاوت ميانگين گروه آموزش نظمجويى هيجانى با آموزش ذهن ذهن

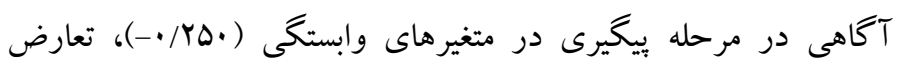

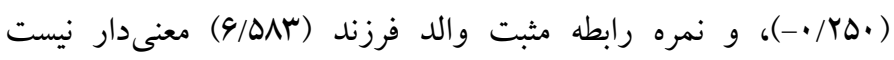

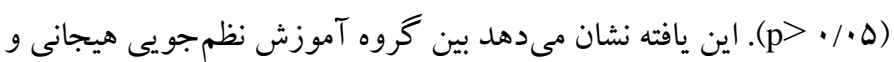

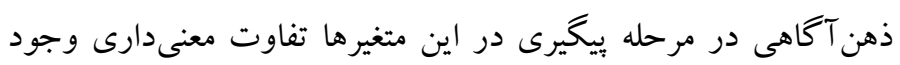
ندارد.
اين يافته نشان مىدهد كه بين گروه آموزش نظمجويى هيجانى و ذهن آكاهى در مرحله ييش آزمون تفاوت معنىدارى وجود ندارد و گرووهها

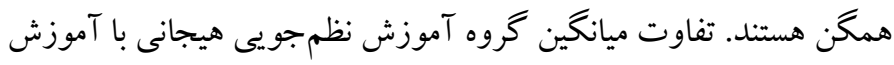

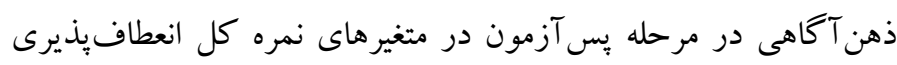

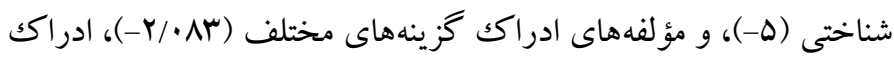

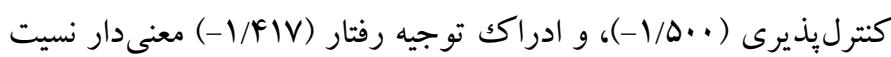
$(p>\cdot / \cdot \Delta)$ اين يافته نشان مىدهد بين گروه آموزش نظم جويى هيجانى و ذهن آكاهى

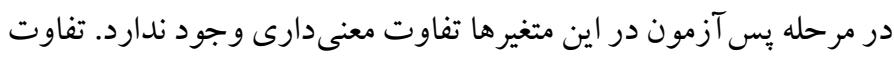

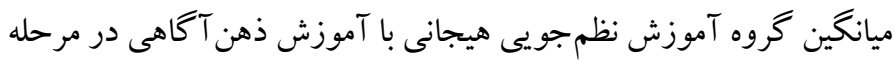

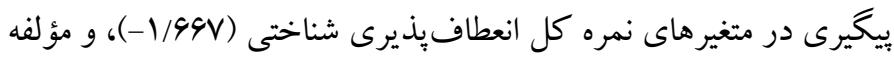

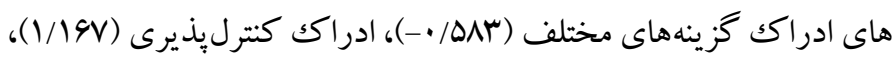

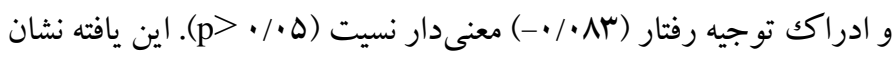
مىدهد بين گروه آموزش نظمجويى هيجانى و ذهن آكاهى در مر مرحله يبيخيرى در اين متغيرها تفاوت معنى دارى وجود ندو ندارد.

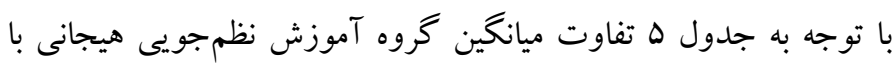

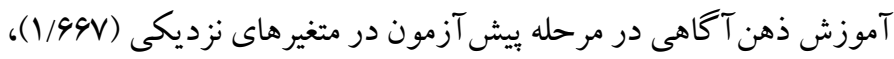

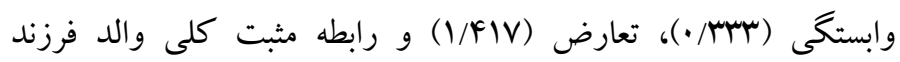

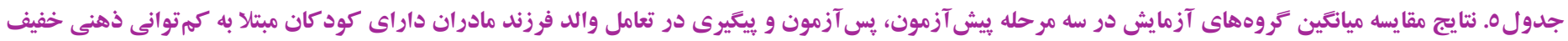

\begin{tabular}{|c|c|c|c|c|c|}
\hline سطح معنى دارى & خطاى استاندارد بر آورد & تفاوت ميانكين گروه آزمايش با گواه & 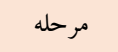 & & \\
\hline$\cdot / 9 \vee 9$ & $\cdot / A F \Delta$ & $1 / 99 \mathrm{~V}$ & ي بيش آزمون & & \multirow{12}{*}{ تعامل والد فرزند } \\
\hline$\cdot /$ / 10 & $1 / \cdot r y$ & 1/VQ. & يس آزمون & 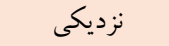 & \\
\hline$\bullet \cdot r$ & $\cdot / \mathrm{Q \Delta}$ & r/QIV & بيخيرى & & \\
\hline$\cdot / 9$ Y & $\cdot / 9 \cdot 9$ & 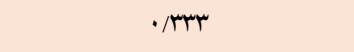 & ي ي آزمون & & \\
\hline.$/ 914$ & $\cdot / \mathrm{Val}$ & $-\cdot / V \Delta$ & يس آزمون & وابستكى & \\
\hline . /949 & $\cdot / M V$ & $-\cdot / Y Q$ & 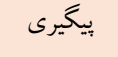 & & \\
\hline - /AYA & r/FIY & I/FIV & بيش آزمون & & \\
\hline - /arr & $r / M T q$ & 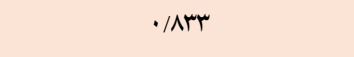 & يس آزمون & ت تعارض & \\
\hline ./99ץ & $r / l 14$ & $-\cdot / r \Delta$. & ي ييخيرى & & \\
\hline - /A9Y & $1 / 941$ & $-\cdot / V \Delta$ & ييش آزمون & & \\
\hline$\cdot / r \cdot 1$ & $r / r l$. & F/ATr & يس آزمون & رابطه مثبت كلى & \\
\hline ./lor & r/FaF & 9/DAr & ي ييخيرى & & \\
\hline
\end{tabular}


دهى هيجانى مى شوند. بنابر اين، بهنظر مىرسد عامل ميانجى گر بالقوه ديخر

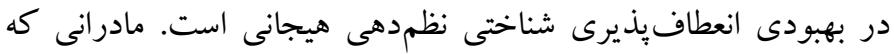

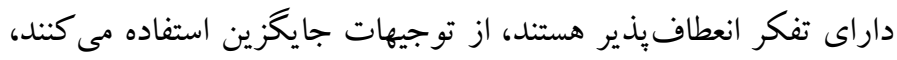

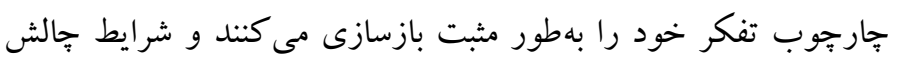

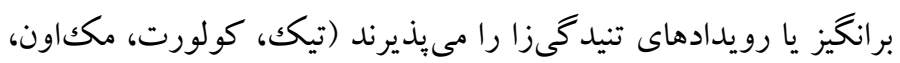

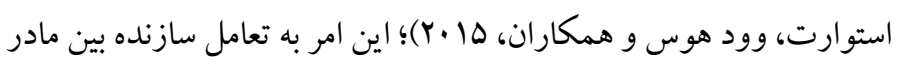
و كودك كمتو انى ذهنى منجر مى گردد كه در اثر مداخلات تنظم هيجان و ذهن آكاهى صورت مى بذ يذيرد. در مجموع مى توان كفت كه آموزش نظم جويى هيجانى بهدليل سود برد بردن

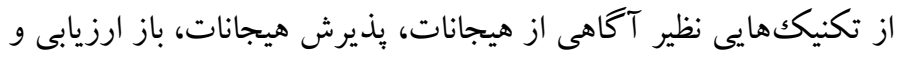

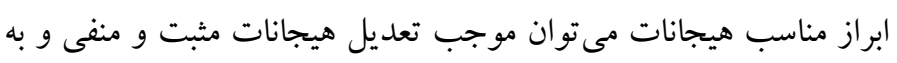

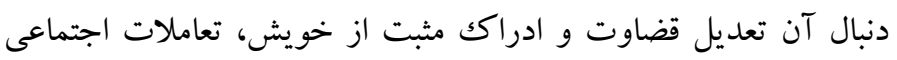
مثبت و افزايش فعاليت در باسخ به موقعيتهاى اجتماعى در افراد شود

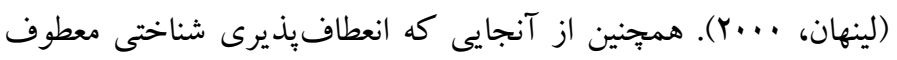

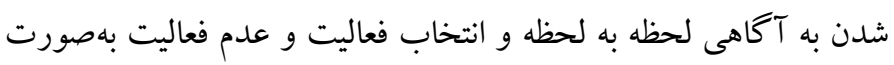

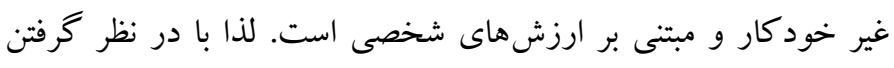

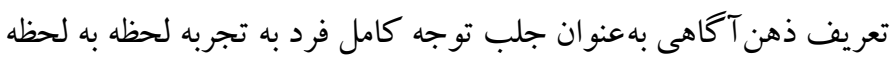

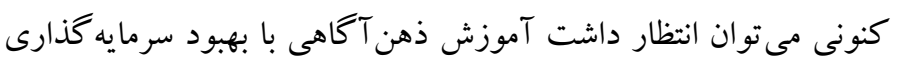

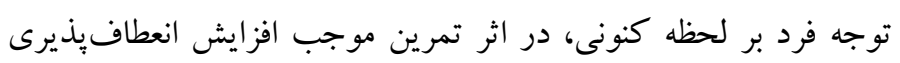

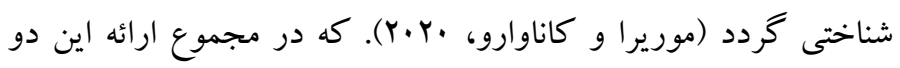

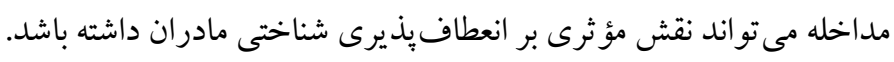

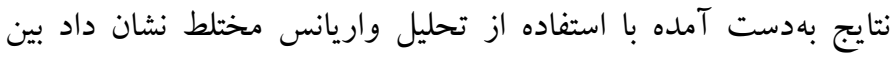

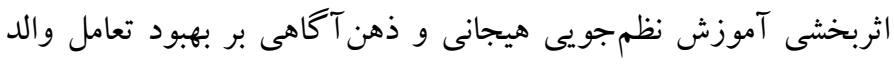

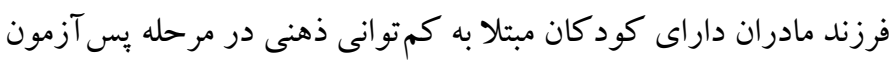

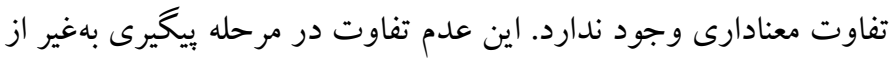

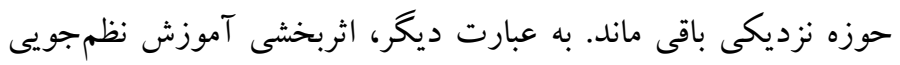

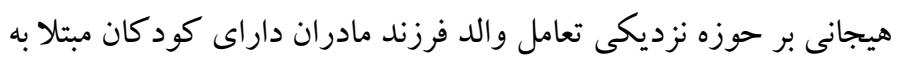

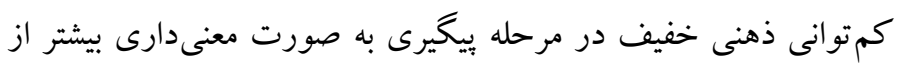

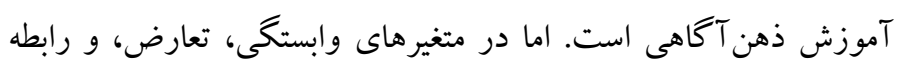
مثبت كلى والد فرزند تفاوتى بين اين دو روش آموزش وجودي آدود ندارد و هر

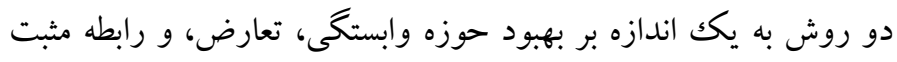

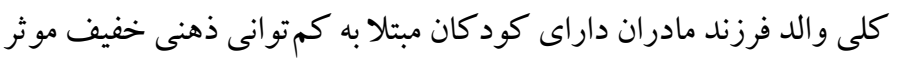

بحث و نتيجه تيرى همانطور كه كفته شد؛ يزوهش حثى حاضر با هدف مقايسه اثربخشى آموزش

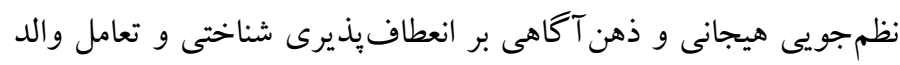

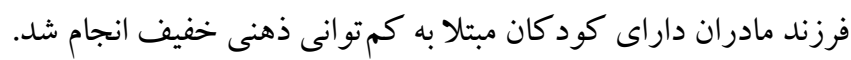

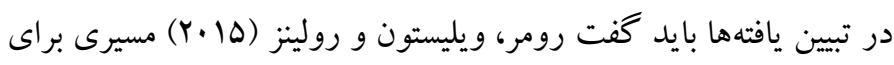

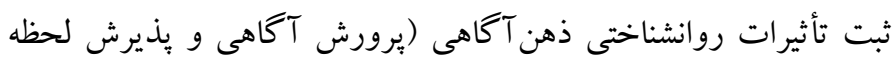

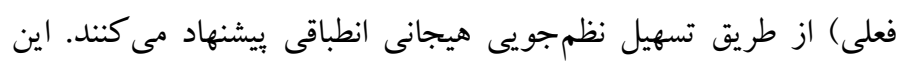

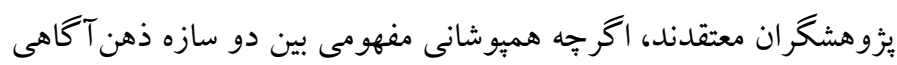
و نظمجويى هيجانى بيجيجيده است اما مجموعهاى رو به رشد از مطالعات

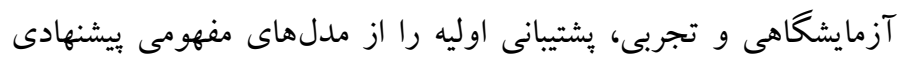

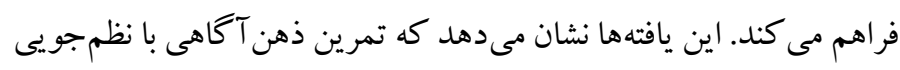

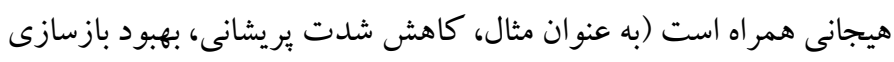

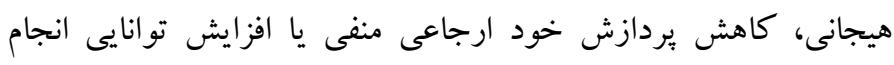

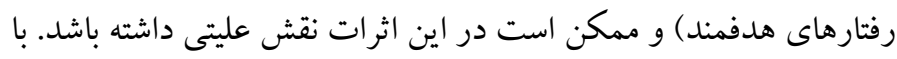

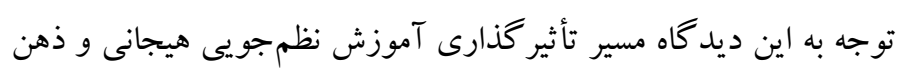

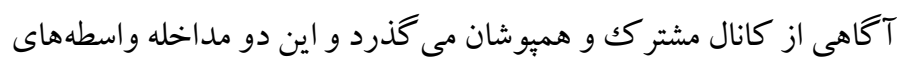

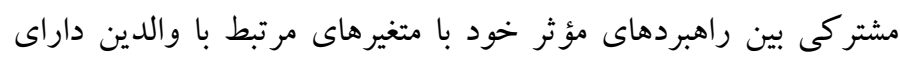

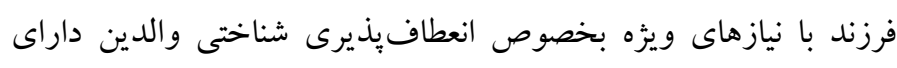

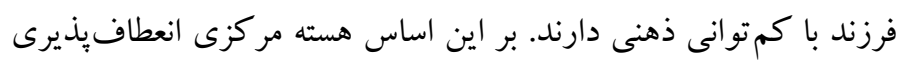

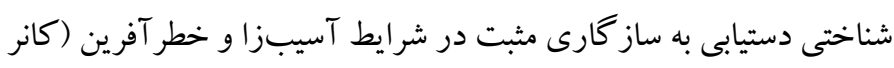

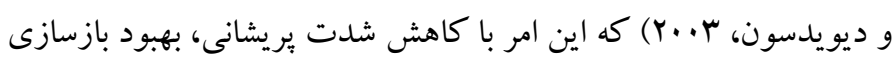
هيجانى، كاهش يردازش خود ارجاعى منفى يا افزايش تو انايى انجام

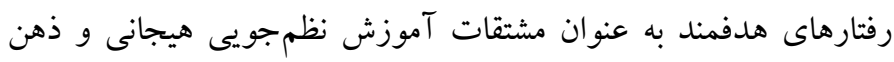

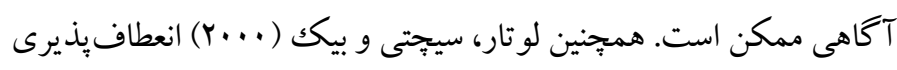

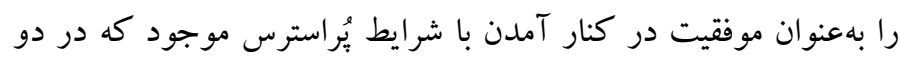

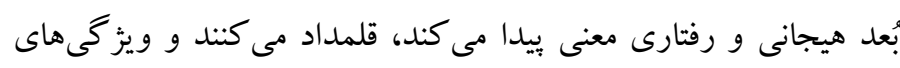

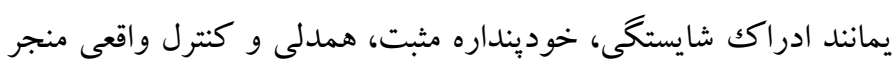

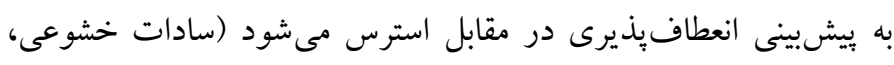

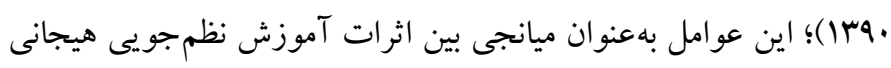

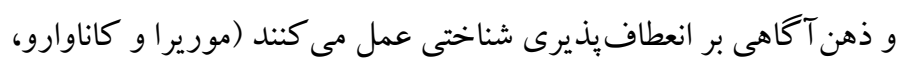

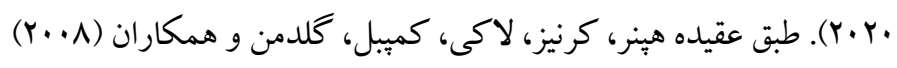

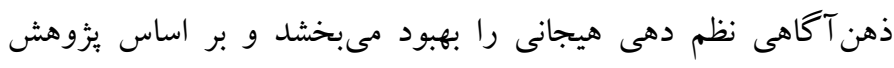

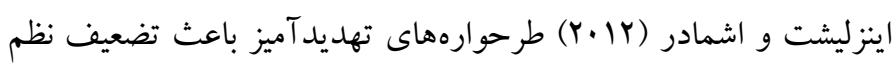


نظمجويى هيجانى از طريق واسطهاى مشتركك بر تعامل والد - كودكك

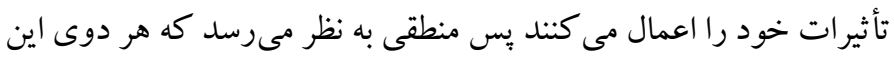
شيوه مداخله به يكك اندازه منجر به بهبود تعامل والد - فرزند و مؤلفههاى

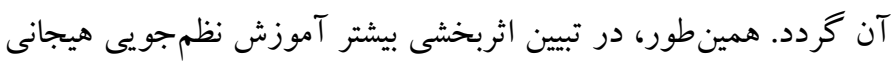

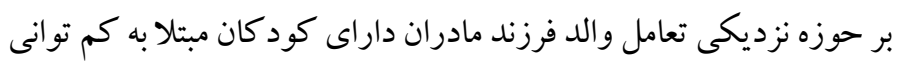

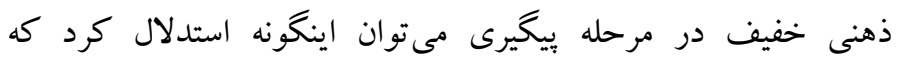
راهبردهاى نظمجويى هيجانى براى تثبيت اثربخشى كامل خود به به زمان مان

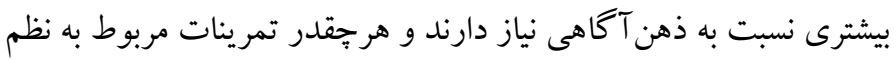

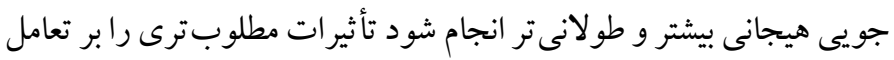

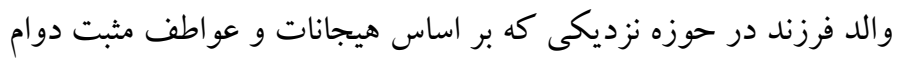

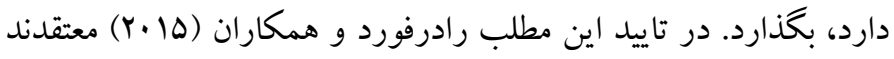
نظم جويى هيجانها، بهعنوان توانايى تأثير گذارى بر تجربه و ابراز احساسات فرد، يكك مهارت بيجيده است كه در طول زمان تكامل مى يابد و تأثيرات بهات

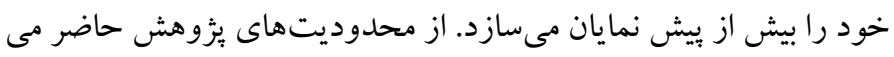
توان كفت كه به علت مشكلات اجرايى در تعيين نمونه امكان انتخاب تصادفى ميسر نشد و فقط جايدهى تصادفى انجام شدو اين يزوهش بر روى لمئه

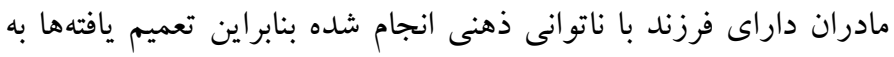

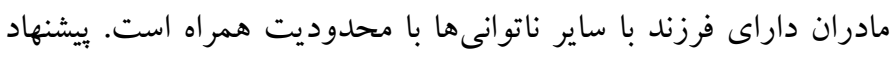

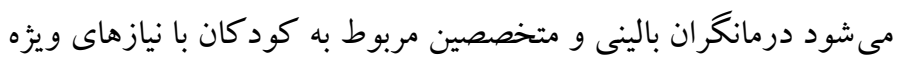

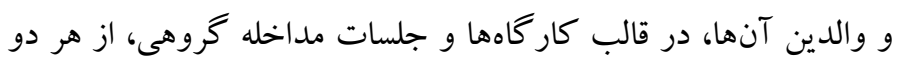
آموزش نظمجويى هيجانى و ذهن آكاهى به عنوان درمانهاى مكمل دهل دهل

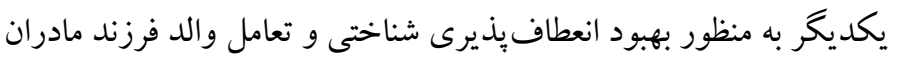
داراى كود كان مبتلا به كم توانى ذهنى خفيف استفاده گردد.

ملاحضات اخلاقى بيروى از اصول اخلاق ثؤوهش: از كليه شر كت كند كان رضايت آكاهانه دريافت

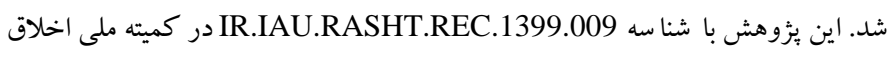

به ثبت رسيده است.

حامى مالى : اين يزوهش در قالب رساله دكترى و بدون حمايت مالى مىباشد. نقش هر يكك از نويسند كان: همه نويسند كان در تدوين مقاله مشاركت دا شتهاند و نسخه نهايى را تأييد كردند. تضاد منافع: نويسند كان هيج تضاد منافعى در رابطه با اين يزوهش اعلام تلام نمىنمايند. ت شكر و قدردانى: نوي سند كان بر خود لازم مىدانند كه از همه مشاركت كنند كان در يثزوهش تشكر داشته باشند.
هستند. با بررسى ييشينهاى يُزوهش مطالعهاى مرتبط با نتايج اين بخش يافت نشد. در تبيين عدم تفاوت در اثربخشى آموزش نظمجويى هيجانى و ذهن

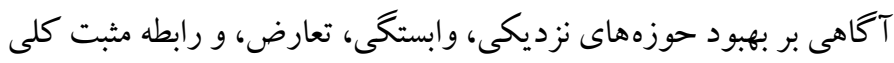

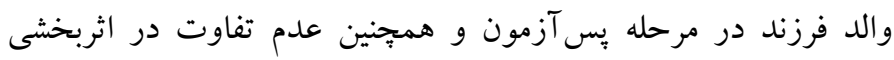

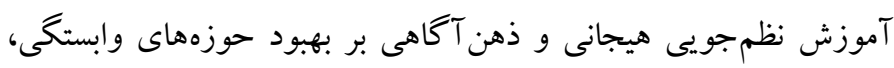

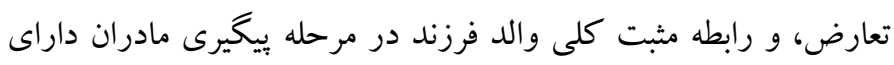

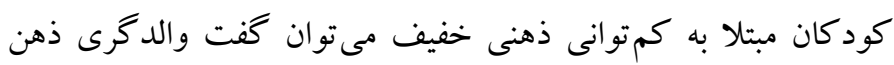

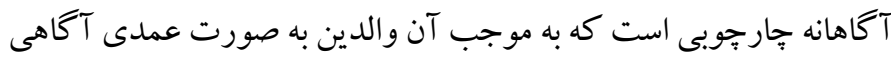

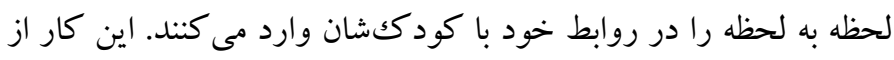

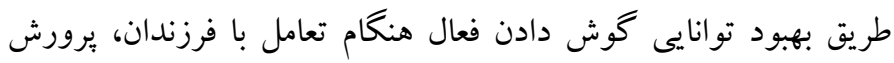

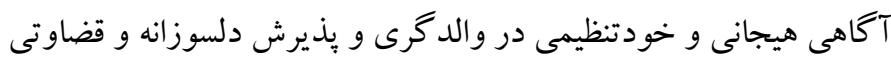

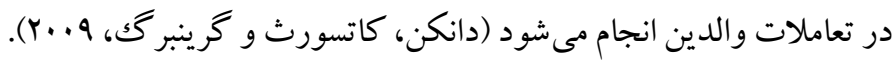

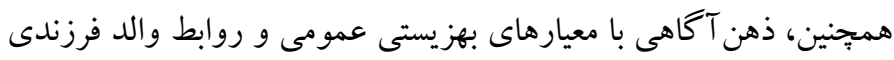
مرتبط است و نظمجويى هيجانى بهطور بالقوه زمينهساز اين تأثيرات

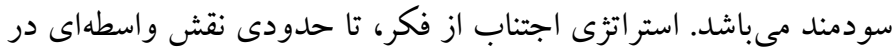

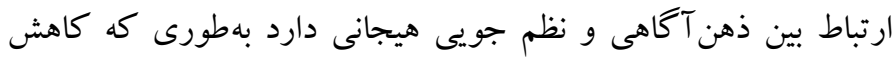

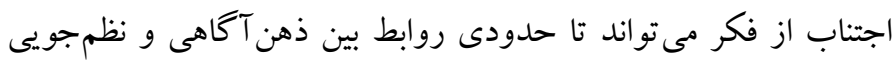

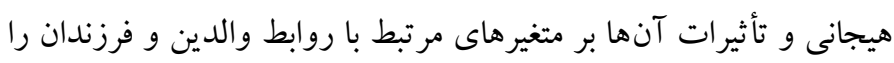

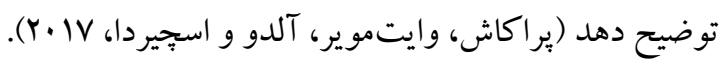

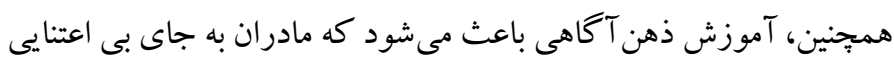

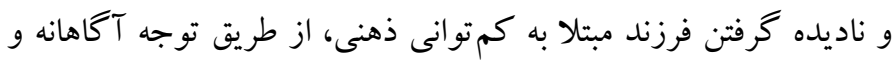

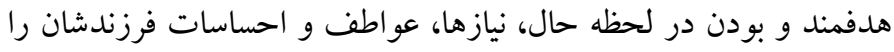

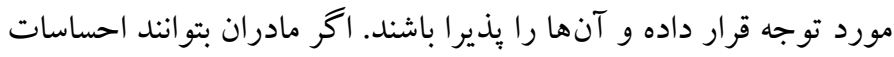
خود و فرزندشان را شناسايى نموده و نسبت به آنها آكاهى بيدا كنند، قادر

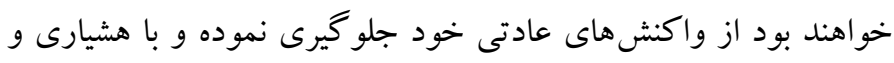

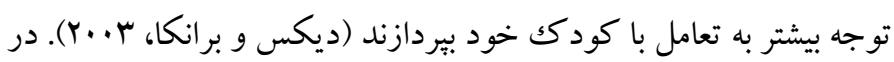

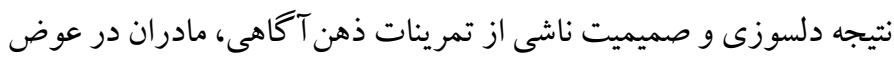

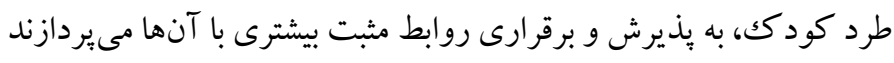

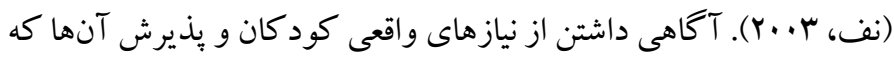

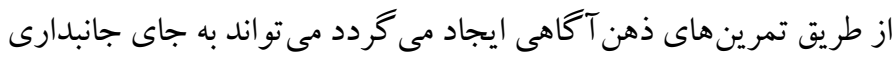

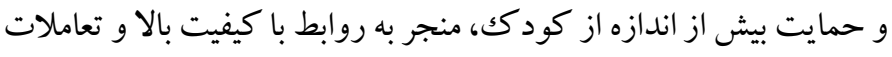

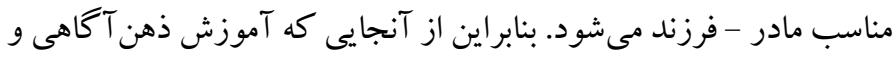




\section{References}

Abareshi, Z., Tahmasian, K., Mazaheri, M. A., \& Panaghi, L. (2009). The impact of psychosocial Child Development training program, done through improvement of mother-child interaction, on parental self-efficacy and relationship between mother and child under three. Journal of Research in Psychological Health, 3(3),49-58. (Persian). [Link]

Abyar, Z., Rahimi, E., Ahmadi Nasrabad Sofla, S., Maredpour, A., \& Zamani, N. (2017). Effectiveness of Emotion Regulation Training on Mental Health of Mothers by Children with Mental Disorders. Health Research Journal, 2(1), 17-23. (Persian). [Link]

Agazzi, H., Tan, S. Y., Ogg, J., Armstrong, K., \& Kirby, R. S. (2017). Does parent-child interaction therapy reduce maternal stress, anxiety, and depression among mothers of children with autism spectrum disorder. Child \& Family Behavior Therapy, 39(4), 283-303. [Link]

Aghdasi, N., Soleimanian, A. A., \& Asadi Gandomani, R. (2019). The effectiveness of mindfulness training on emotional schemas mothers of children with Cerebral Palsy. Archives of Rehabilitation, 20(1), 86-97. (Persian). [Link]

Ahmadi, T., Kheirati, H., \& Ghobari Bonab, B. (2019). Effectiveness of mindfulness-based training on cognitive emotion regulation and cognitive flexibility in mothers of children with Learning Disabilities. Empowering Exceptional Children, 10(3), 125-138. (Persian). [Link]

Amir, F. (2012). The present study investigated the effects of play therapy based on child parent relationship therapy on improving the parenting styles. Family Counseling and Psychotherapy, 1(3), 473-389. (Persian). [Link]

Asgari, M., \& Matini, A. (2020). The effectiveness of emotion regulation training based on gross model in reducing impulsivity in smokers. Counseling Culture and Psycotherapy, 11(42), 205-230. (Persian). [Link]

Azeem, M. W., Dogar, I. A., Shah, S., Cheema, M. A., Asmat, A., Akbar, M., \& Haider, I. I. (2013). Anxiety and depression among parents of children with intellectual disability in Pakista. Journal of the Canadian Academy of Child and Adolescent Psychiatry, 22(4), 290-295. [Link]

Bireda, A. D., \& Pillay, J. (2018). Perceived parent-child communication and well-being among Ethiopian adolescents. International Journal of Adolescence and Youth, 23(1), 109-117. [Link]
Campbell-Sills, L., Cohan, S. L., \& Stein, M. B. (2006). Relationship of resilience to personality, coping, and psychiatric symptoms in young adults. Behavior Research and Therapy, 44(4), 585-599. [Link]

Connor, K. M., \& Davidson, J. R. (2003). Development of a new resilience scale: The Connor-Davidson resilience scale (CD-RISC). Depression and anxiety, 18(2), 76-82. [Link]

Curran, T., Worwood, J., \& Smart, J. (2019). Cognitive flexibility and generalized anxiety symptoms: The mediating role of destructive parent-child conflict communication. Communication Reports, 32(2), 57-68. [Link]

Dennis, J. P., \& Vander Wal, J. S. (2010). The cognitive flexibility inventory: Instrument development and estimates of reliability and validity. Cognitive Therapy Research, 34, 241-253. [Link]

Dix, T., \& Branca, S. H. (2003). Parenting as a goalregulation process. Handbook of dynamics in parent-child relations, 167-187. [Link]

Driscoll, K., \& Pianta, R. C. (2011). Mothers' and Fathers' Perceptions of Conflict and Closeness in ParentChild Relationships during Early Childhood. Journal of Early Childhood \& Infant Psychology, 12 (7), 1-24. [Link]

Duncan, L. G., Coatsworth, J. D., \& Greenberg, M. T. (2009). A model of mindful parenting: Implications for parent-child relationships and prevention research. Clinical child and family psychology review, 12(3), 255-270. [Link]

Fazli, N., \& Sajjadian, I. (2017). The effectiveness of mindful parenting education on child behavior's problems and parenting stress among mothers with attention-deficit hyperactivity disorder. Knowledge \& Research in Applied Psychology, 17(3), 26-35. (Persian). [Link]

Gershy, N., \& Gray, S. A. (2020). Parental emotion regulation and mentalization in families of children with ADHD. Journal of attention disorders, 24(14), 2084-2099. [Link]

Gogoi, R. R., Kumar, R., \& Deuri, S. P. (2017). Anxiety, depression, and quality of life in mothers of children with intellectual disability. Open Journal of Psychiatry \& Allied Sciences, 8(1), 71-75. [Link]

Griffith, G. M., Hastings, R. P., Williams, J., Jones, R. S., Roberts, J., Crane, R. S., \& Edwards, R. T. (2019). Mixed experiences of a mindfulness-informed intervention: voices from people with intellectual disabilities, their supporters, and therapists. Mindfulness, 10(9), 1828-1841. [Link]

Gross, J. J. (2008). Emotion regulation. In M. Lewis, J. M. Haviland-Jones, \& L. F. Barrett (Eds.), Handbook 
of emotions (pp. 497-512). The Guilford Press. [Link]

Gross, J. J., \& John, O. P. (2003). Individual differences in two emotion regulation processes: implications for affect, relationships, and well-being. Journal of personality and social psychology, 85(2), 348-355. [Link]

Heppner, W. L., Kernis, M. H., Lakey, C. E., Campbell, W. K., Goldman, B. M., Davis, P. J., \& Cascio, E. V. (2008). Mindfulness as a means of reducing aggressive behavior: Dispositional and situational evidence. Aggressive Behavior: Official Journal of the International Society for Research on Aggression, 34(5), 486-496. [Link]

Hollis-Walker, L., \& Colosimo, K. (2011). Mindfulness, self-compassion, and happiness in non-meditators: A theoretical and empirical examination. Personality and Individual differences, 50(2), 222227. [Link]

Hosseinkhanzadeh A A, Taher M, Seyednuri S Z, Yahyazadeh. A., \& Esapour, M. (2014). Relationship between interaction parent-child with addictability rate and heterosexual orientation in students. Scientific Quarterly of Research on Addiction, 7(28),59-74. (Persian). [Link]

Huberty, C. J. (2002). A history of effect sizes indices. Educational Psychology Measurement. 62, 227240. [Link]

Inzlicht, M., \& Schmader, T. (2012). Stereotype threat: Theory, process, and application. Oxford University Press. [Link]

Javadian, S. R., \& Fathi, M. (2018). The Effectiveness of Emotional Regulation Training on Negative Affect and Resilience of Mothers with Disabled Children. Iranian Journal of Psychiatric Nursing (IJPN), 6(5), 25-33. (Persian). [Link]

Javadian, S. R., Khaleghi, L., \& Fathi, M. (2018). The Effectiveness of Emotional Regulation Training on Negative Affect and Resilience of Mothers with Disabled Children. Iranian Journal of Psychiatric Nursing, 6(5), 25-33. (Persian). [Link]

Jones, L., Gold, E., Totsika, V., Hastings, R. P., Jones, M., Griffiths, A., \& Silverton, S. (2018). A mindfulness parent well-being course: Evaluation of outcomes for parents of children with autism and related disabilities recruited through special schools. European Journal of Special Needs Education, 33(1), 16-30. [Link]

Kabat-Zinn, J. (2003). Mindfulness-based interventions in context: past, present, and future. Clinical psychology: Science and practice, 10(2), 144-156. [Link]
Kabat-Zinn, J. (2015). Mindfulness. Mindfulness, 6(6), 1481-1483. [Link]

Kamali, A., Vaghee, S., Asgharipour, N., \& Behnam vashani, H. R. (2016). The impact of Emotion Regulation Training on Mental health in Mothers of Children with attention deficit/hyperactivity Disorder. Journal of Torbat Heydariyeh University of Medical Sciences, 4(3),16-23. (Persian). [Link]

Khaleghipour, Sh., \& Zargar, F. (2014). Effect of Mindfulness-based cognitive therapy on depression and life expectancy mentally retarded children. Journal of Research in Behavioural Sciences, 12(2), 264-273. (Persian). [Link]

Kohandani, M., \& Abolmaali Alhosseini, K. (2017). Factor structure and psychometric properties of Persian version of cognitive flexibility of Dennis, Vander Wal and Jillon. Psychological methods and models, 29(4), 53-70. (Persian). [Link]

Linehan, M. (2000). Cognitive-behavioral Treatment of Borderline Personality Dosorder. New York: Guilford Press. [Link]

Lo, H. H. M., Chan, S. K. C., Szeto, M. P., Chan, C. Y. H., \& Choi, C. W. (2017). A feasibility study of a brief mindfulness-based program for parents of preschool children with developmental disabilities. Mindfulness, 8(6), 1665-1673. [Link]

Lo, H. H., Wong, S. W., Wong, J. Y., Yeung, J. W., Snel, E., \& Wong, S. Y. (2020). The effects of familybased mindfulness intervention on ADHD symptomology in young children and their parents: a randomized control trial. Journal of attention disorders, 24(5), 667-680. [Link]

Luthar, S.S., Cicchetti, D., \& Bec, B. (2000). The Construct of Resilience: A Critical Evaluation and Guidelines for Future Work. Child Development, 71(3), 543-562. [Link]

Matin, H., Akhavan Gholami, M., \& Ahmadi, A. (2018). The effectiveness of emotion regulation teaching on the parent_child interaction and those mothers that have learning disabilities children. Journal of Learning Disabilities, 8(1), 70-89. (Persian). [Link]

McRae, K., \& Gross, J. J. (2020). Emotion regulation. Emotion, 20(1), 1-9. [Link]

Moradikia, H., Arjmandnia, A. A., \& Ghobari Bonab, B. (2016). Effectiveness of emotion regulation training on psychological well-being of Mothers of students with intellectual disability. J Pediatr Nur, 3(1), 5160. (Persian). [Link]

Moradikia, H., Sattarpour Iranaghi, F., \& Emamgholian, S. (2017). Compare the effectiveness of emotion regulation and resilience training on psychological well-being of mothers of students with intellectual 
disability. Iranian Journal of Health Education and Health Promotion, 5(3), 213-223. (Persian). [Link]

Moreira, H., \& Canavarro, M. C. (2020). Mindful Parenting is Associated with Adolescents' Difficulties in Emotion Regulation Through Adolescents' Psychological Inflexibility and SelfCompassion. Journal of youth and adolescence, 49(1), 192-211. [Link]

Neff, K. D. (2003). The development and validation of a scale to measure self-compassion. Self and identity, 2(3), 223-250. [Link]

Petcharat, M., \& Liehr, P. (2017). Mindfulness training for parents of children with special needs: Guidance for nurses in mental health practice. Journal of Child and Adolescent Psychiatric Nursing, 30(1), 3546. [Link]

Potharst, E. S., Leyland, A., Colonnesi, C., Veringa, I. K., Salvadori, E. A., Jakschik, M., \& Zeegers, M. A. (2020). Does Mothers' Self-Reported Mindful Parenting Relate to the Observed Quality of Parenting Behavior and Mother-Child Interaction. Mindfulness, 12 (2), 1-13. [Link]

Pourmohamadreza-Tajrishi M, Ashouri M, Afrooz GA, Arjmandnia, A. A., \& Ghobari-Bonab, B. (2015). The Effectiveness of positive parenting program (Triple-P) training on interaction of mother-child with intellectual disability. Rehabilitation, 16(2),128-137. (Persian). [Link]

Prakash, R. S., Whitmoyer, P., Aldao, A., \& Schirda, B. (2017). Mindfulness and emotion regulation in older and young adults. Aging \& mental health, 21(1), 77-87. [Link]

Roemer, L., Williston, S. K., \& Rollins, L. G. (2015). Mindfulness and emotion regulation. Current Opinion in Psychology, 3, 52-57. [Link]

Rutherford, H. J., Wallace, N. S., Laurent, H. K., \& Mayes, L. C. (2015). Emotion regulation in parenthood. Developmental Review, 36, 1-14. [Link]

Sadat, M. (2009). Resilience from Developmental Psychology Perspective. Educational researches, 5(19), 1-32. (Persian). [Link]

Safikhani, F., Eftekhar Saadi, Z., Naderi, F., \& Marashian, F. S. (2020). The Effectiveness of Cognitive Therapy based on Conscious and Mental Imagery Grammatical on Spirituality and Emotional Processing of Mothers of Students with Autism Spectrum Disorder. Educational Development of Judishapur, 11(3), 427-445. (Persian). [Link]

Shalani, B., Sadeghi, S., \& Rashidiyan, S. (2019). Executive functions in parents of children with and without autism spectrum disorder. Shenakht Journal of Psychology and Psychiatry, 6(4),90-99. (Persian). [Link]
Shareh, H., Farmani, A., \& Soltani, E. (2014). Investigating the reliability and validity of the Cognitive Flexibility Inventory (CFI-I) among Iranian university students. Practice in Clinical Psychology, 2(1), 43-50. [Link]

Sheykholeslami, A., Mohammad, N., \& Seyedesmaili Ghomi, N. (2016). Comparing the parenting stress, happiness and cognitive flexibility of mothers with intellectually disable and learning disable children. Journal of Learning disabilities, 5(4), 25-42. (Persian). [Link]

Shokri, A., Kazemi, R., Narimani, M., \& Taklavi, S. (2020). Comparison of the effectiveness of mindfulness-based cognitive therapy and emotion regulation training on parental stress of mothers with aggressive children. Quarterly Journal of Child Mental Health, 7(1), 205-219. (Persian). [Link]

Singh, N. N., Lancioni, G. E., Karazsia, B. T., Myers, R. E., Hwang, Y. S., \& Anālayo, B. (2019). Effects of mindfulness-based positive behavior support (MBPBS) training are equally beneficial for mothers and their children with autism spectrum disorder or with intellectual disabilities. Frontiers in Psychology, 10(385), 1-36. [Link]

Stevens, J. (1996). Applied multivariate statistics for the social sciences (3rd Ed). Mahwah, NJ: Lawrence Erlbaum. [Link]

Teasdale, J. D., Segal, Z. V., Williams, J. M., Ridgeway, V. A., Soulsby, J. M., \& Lau, M. A. (2000). Prevention of relapse/recurrence in major depression by mindfulness-based cognitive therapy. Journal of Consulting and Clinical Psychology, 68(11), 615-625. [Link]

Tick, B., Colvert, E., McEwen, F., Stewart, C., Woodhouse, E., Gillan, N., Rijsdijk, F. (2015). Autism Spectrum Disorders and Other Mental Health Problems: Exploring Etiological Overlaps and Phenotypic Causal Associations. Journal of the American Academy of Child \& Adolescent Psychiatry, 55(2), 106-113. [Link]

Tick, B., Colvert, E., McEwen, F., Stewart, C., Woodhouse, E., Gillan, N., Rijsdijk, F. (2015). Autism Spectrum Disorders and Other Mental Health Problems: Exploring Etiological Overlaps and Phenotypic Causal Associations. Journal of the American Academy of Child \& Adolescent Psychiatry, 55(2), 106-113. [Link] 